\title{
Parental supply of alcohol and alcohol consumption in adolescence: \\ Prospective cohort study
}

\begin{abstract}
Richard P Mattick $^{\mathrm{a}}, \mathrm{PhD}$, Monika Wadolowski ${ }^{\mathrm{b}}, \mathrm{PhD}$, Alexandra Aiken ${ }^{\mathrm{a}}$, BPsych(Hons), Philip Clare $^{\mathrm{a}}$, MBiostats, Delyse Hutchinson ${ }^{\mathrm{c}}, \mathrm{PhD}$, Jackob Najman ${ }^{\mathrm{d}}, \mathrm{PhD}$, Tim Slade ${ }^{\mathrm{a}}, \mathrm{PhD}$, Raimondo Bruno $^{\mathrm{e}}, \mathrm{PhD}$, Nyanda McBride ${ }^{\mathrm{f}}, \mathrm{PhD}$, Louisa Degenhardt ${ }^{\mathrm{a}}, \mathrm{PhD}$, Kypros Kypri $^{\mathrm{g}}, \mathrm{PhD}$
\end{abstract}

Affiliations: ${ }^{a}$ National Drug \& Alcohol Research Centre, University of New South Wales (UNSW) Australia, Sydney NSW 2052 Australia; ${ }^{\mathrm{b}}$ The Kirby Insitute, University of New South Wales (UNSW) Australia, Sydney NSW 2052 Australia; ${ }^{\mathrm{C}}$ School of Psychology, Deakin University, Melbourne VIC 3125 Australia; ${ }^{\mathrm{d}}$ Queensland Alcohol and Drug Research and Education Centre, University of Queensland, Brisbane QLD 4072 Australia; ${ }^{\text {e School of }}$ Psychology, University of Tasmania, Hobart TAS 7000 Australia;

${ }^{\mathrm{f}}$ National Drug Research Institute, Curtin University, GPO Box U1987, Perth WA 6845 Australia; ${ }^{\mathrm{g}}$ Centre for Clinical Epidemiology and Biostatistics, School of Medicine and Public Health, University of Newcastle, Newcastle NSW 2308 Australia.

Address correspondence to: Richard P Mattick, NDARC, Faculty of Medicine, UNSW Australia, Sydney, NSW, 2052, Australia, [r.mattick@unsw.edu.au] +61 293850331.

Short title: Parental supply of alcohol

Funding Source: This research was funded by: a 2010-2014 Australian Research Council Discovery Project Grant (DP:1096668) to RPM, JN, KK, TS, DH, supplemented by funds from: two Australian Rotary Health Mental Health Research Grants to RPM, MW, AA, JN, KK, TS, DH, RB; an Australian Rotary Health Whitcroft Family PhD Scholarship and an Australian 
Postgraduate Award to MW; National Health and Medical Research Council Principal Research Fellowship Grants to RPM (APP1045318), and KK (GNT0188568, APP1041867); National Health and Medical Research Council Project Grants to RPM for a Longitudinal Cohorts Research Consortium (GNT1009381 and GNT1064893); a Research Innovation Grant from the Australian Foundation for Alcohol Research and Education to RPM, JN, KK, TS, DH, RB, and MW; the National Drug \& Alcohol Research Centre, UNSW Australia, which is supported by an Australian Government Substance Misuse Prevention and Service Improvements Grant.

Financial Disclosure: We have no financial relationships relevant to this article to disclose.

Conflict of Interest: None.

Clinical Trial Registration: ClinicalTrials.gov (NCT02280551).

Abbreviations: IRB=Institutional review board; IRR=Incident Rate Ratio; OR=odds ratio; $\mathrm{SES}=$ socio-economic status.

Contributors' Statements: Drs Mattick, Najman, Kypri, Slade, and Hutchinson conceptualised the study, and with Dr Wadolowski, Ms Aiken, Dr Bruno, and Dr McBride, designed the data collection methods. Dr Wadolwski, Ms Aiken, and Dr Mattick acquired the data. Mr Clare and Dr Mattick conducted the data analyses, and Dr Mattick and Mr Clare drafted the manuscript. All authors provided substantial contributions to the interpretation of the results, and all critically revised the manuscript for important intellectual content, and approved the final manuscript as submitted. All authors have agreed to be accountable for all aspects of the work. 


\section{Abstract}

Background Parents are a major supplier of alcohol to adolescents, yet there is limited research examining the impact of this on adolescent alcohol use. This study investigates associations between parental supply of alcohol, supply from other sources, and adolescent drinking, adjusting for child, parent, family, and peer variables.

Methods A cohort of 1927 adolescents were surveyed annually from 2010- 2014. Measures include consumption of whole drinks and binge drinking ( $>4$ drinks on any occasion); parental supply of alcohol, supply from other sources; child, parent, family, and peer covariates.

Results After adjustment, adolescents supplied alcohol by parents had higher odds of drinking whole beverages (odds ratio [OR] 1.80, 95\% CI 1.33-2.45), than those not supplied by parents. However, parental supply was not associated with bingeing, and those supplied alcohol by parents typically consumed fewer drinks per occasion (incidence-rate ratio, 0.86; 95\% CI, 0.770.96) than adolescents supplied only from other sources. Adolescents obtaining alcohol from non-parental sources had increased odds of drinking whole beverages (OR 2.53; 95\% CI 1.863.45) and bingeing (OR 3.51; 95\% CI 2.53-4.87).

Conclusions Parental supply of alcohol to adolescents was associated with increased risk of drinking, but not bingeing. These parentally-supplied children also consumed fewer drinks on a typical drinking occasion. Adolescents supplied alcohol from non-parental sources had greater odds of drinking and bingeing. Further follow-up is necessary to determine whether these patterns continue, and to examine alcohol-related harm trajectories. Parents should be advised that supply of alcohol may increase children's drinking.

MeSH keywords Alcohol drinking, adolescent, cohort studies, epidemiology, longitudinal studies 


\section{Parental supply of alcohol and alcohol consumption in adolescence: \\ Prospective cohort study}

\section{Introduction}

Adolescent drinking is associated with developing non-communicable diseases (Patton et al., 2012, Swendsen et al., 2012), being the leading risk factor for disability-adjusted-life-years lost in 10-24-year-olds (Gore et al., 2011). Surprisingly then, parents are a major source of alcohol consumed by children. Approximately a third of adolescents in US, European, and Australian studies (Hearst et al., 2007, White and Bariola, 2012, Henderson et al., 2013) report parental supply. Reasons cited for parental supply include: parental desire to "socialize" children into responsible drinking, "inoculating" them from heavy consumption (Donovan and Molina, 2008, Gilligan et al., 2012, Jackson et al., 2012); parental concern that peers' parents will provide alcohol anyway (Gilligan et al., 2012, Jackson et al., 2012, Wadolowski et al., 2016); and supply at cultural/religious, or celebratory events (Gilligan et al., 2012, Jackson et al., 2012). Yet, the quality of evidence on whether parental supply is associated with more, or less, adolescent drinking is compromised by design and analytic limitations.

While a recent review concluded that parental supply was "generally associated" with increased child drinking (Kaynak et al., 2014), that view was qualified by study design limitations. Ignoring the cross-sectional studies - of little assistance in understanding the impact of parental supply - seven cohorts showed associations between parental supply and drinking (Kaynak et al., 2014). Yet, assessments were limited to one (Shortt et al., 2007, Livingston et al., 2010), or two follow-up occasions (Jackson et al., 1999, Komro et al., 2007, Van Der Vorst et al., 2010, Danielsson et al., 2011, McMorris et al., 2011), in quite late adolescence (18-19-years-of-age (Livingston et al., 2010)) or in early adolescence (10-12-(Jackson et al., 1999), 12-13-(Shortt et al., 2007), or 12-14-years-of-age (Komro et al., 2007, McMorris et al., 2011)) hampering 
conclusions about both the development and the sequelae of parental supply. One study did span 13-15-years-of-age (Jackson et al., 1999), and a key study assessed 13-16-years-of-age (Van Der Vorst et al., 2010). Yet, these two studies left unmeasured known predictors of adolescent drinking and potential confounders, including: parental/familial alcohol problems (Jackson et al., 1999, Van Der Vorst et al., 2010), parental drinking (Jackson et al., 1999), child externalising and other substance use (Van Der Vorst et al., 2010), and child age (Jackson et al., 1999, Van Der Vorst et al., 2010). Incomplete control for demographics and risk factors was noted in all seven cohorts (Kaynak et al., 2014).

In this last regard, several other parental (Barnes et al., 2000), familial (Nash et al., 2005), child (Zernicke et al., 2010), and peer (Borsari and Carey, 2001) predictors, suggested by parenting and child socialisation research and theory (Oetting and Donnermeyer, 1998, Ajzen, 2002, Real and Rimal, 2007), are associated with adolescent drinking (Fisher et al., 2007, Alati et al., 2010, Donovan and Molina, 2011, Swendsen et al., 2012, Kuperman et al., 2013, Rossow et al., 2015). Factors such as parental/familial drinking/problems (Donovan and Molina, 2011), family intactness (Donovan and Molina, 2011, Kuperman et al., 2013), monitoring of child activities (DiClemente et al., 2001), child externalising/internalising (Crum et al., 2008), and peer substance use (Ary et al., 1999) are often unmeasured. Incomplete adjustment, does not constitute strong analysis, and creates uncertainty about relationships (McCambridge et al., 2011). In addition, when researching associations of parental supply with child drinking, there is also a need to control for alcohol supplied from non-parental sources (other adults, friends, siblings, self-purchased, etc.), referred to hereafter as other supply. Supply of alcohol from nonparental sources has been associated with greater drinking and negative outcomes than parental supply (Foley et al., 2004, Bellis et al., 2007, Dietze and Livingston, 2010), raising the potential for differential harms. However, no prospective study has reported how these different sources 
are associated with adolescent drinking. Overall, the piecemeal picture limits confident conclusions from existing research.

We investigated the associations between exposure to parental supply and other supply of sips or whole drinks of alcohol across four adolescent years (approximately 12-15-years-of-age), and two outcomes - consumption of whole drink(s) (drinking) and binge drinking (bingeing; consuming more than 4 standard drinks on a single occasion, a pattern of drinking that puts the drinker at increased risk of harm (National Health \& Medical Research Council, 2009)) - using longitudinal mixed-model analytic methods, unadjusted and adjusted for the full range of relevant covariates. Guided by the literature and pre-specified aims (Aiken et al., 2015), we hypothesised that while parental supply, other supply, and the covariates, would have significant unadjusted associations with these two outcomes, the adjusted analyses would show parental supply of alcohol to have the greatest odds of drinking and bingeing, given concerns that such provision signals parental permissiveness (Kaynak et al., 2014). 


\section{Methods}

\section{Design}

This longitudinal cohort study is registered (ClinicalTrials.gov: NCT02280551). Institutional review board (IRB), and STROBE statement reporting requirements are met (von Elm et al., 2007).

\section{Sample recruitment and characteristics}

In 2010-2011 a cohort of adolescents and parents were recruited from Grade 7 classes in Sydney, Hobart, and Perth; detailed methods are described elsewhere (Aiken et al., 2015). As in similar research (Jackson et al., 2012), schools made recruitment materials available to students (either by mail or face-to-face at school), but had no other role. Study information packs were distributed to Grade 7 students at participating schools. Parents could submit a form indicating interest in consenting to be in the study, and were eligible to participate if: (a) the child was enrolled in Grade 7; and (b) signed parental consent was provided. Of 2017 parents expressing interest in their child participating, 90 were ineligible, resulting in 1927 adolescents in the cohort (see Figure 1 for details of eligibility and retention); 1910 adolescents provided baseline data, with high retention thereafter $(>85 \%)$. Adolescents were a mean of 12.9-years-of-age at baseline, and similar to the Australian population on important demographic measures: $44.9 \%$ of adolescents were female ( $48.7 \%$ in the population of $12-13$-year-olds); there were 2.6 adolescents per household (1.9 in the population); $79.6 \%$ of the adolescents lived in two-parent households ( $81.0 \%$ in the population); $73.8 \%$ of parents were Australian-born $(72.3 \%$ in the adult population); $73.4 \%$ of parents had post-high school education (67\% in the adult population); $81.2 \%$ of parents were employed ( $80.0 \%$ of males and $65 \%$ of females in the adult population); median household income was in the same range as in the population (Aiken et al., 2015). 
Rates of alcohol use in the adolescent cohort, and of parental drinking and supply, were also similar to those in population surveys. National school student samples (past year alcohol use) and our sample (past 12-month alcohol use) had similar drinking: 21.3\% of 12-year-olds drank in 2011 versus $19.8 \%$ of our sample that year; $32.1 \%$ of 13 -year-olds drank in 2012 , versus $32.9 \%$ of our sample that year (White and Bariola, 2012). School data for 2013 and 2014 are not available, but other national survey data showed a secular decline of approximately $\sim 10 \%$ by 2013 in 12-17-year-olds ever consuming alcohol (Pennay et al., 2015). Applying this secular trend to the school survey data: the national rate of 14-year-olds drinking of $45.9 \%$ should decrease to $\sim 35 \%$ by 2013 (compared with the rate of $37.3 \%$ of 14 -year-olds in the cohort by 2013); and from $60.2 \%$ to $50 \%$ (compared to our rate of $47.9 \%$ of 15 -year-olds in the cohort by 2014). Parental supply was reported by $34.7 \%$ of 15 -year-olds in the cohort (Table 2), compared with $34.9 \%$ of 12-15-year-olds in population surveys (White and Bariola, 2012). Parental frequency of drinking (2.6\% daily, $48.6 \%$ weekly, $38.3 \%$ less than weekly, $10.5 \%$ not in the past 12-months) (Aiken et al., 2015) was similar to Australian adult population use (7.7\% daily, $41.7 \%$ weekly, $33.0 \%$ less than weekly, and $7.7 \%$ not in the past 12 -months) indicating regular alcohol involvement (Australian Institute of Health \& Welfare, 2011).

\section{$\underline{\text { Measures }}$}

\section{Outcome variables (whole standard drink(s) and binge drinking):}

Primary outcomes were: (a) past 12-month consumption of whole standard drink(s) (drinking); (b) binge drinking. A binary variable (no/yes) was constructed to indicate drinking one or more whole standard drink(s) (10g of alcohol), and consumption of more than four standard drinks (no/yes) on any single occasion (Bush et al., 1998), was coded into a binary variable: binge drinking. Current Australian guidelines recommend drinking no more than four standard drinks on a single occasion to reduce the risk of alcohol-related injury, hence binge drinking was coded as consumption as more than four standard drinks on one occasion (National Health \& Medical 
Research Council, 2009). Secondary analyses were conducted of typical quantity consumed on a drinking occasion, and number of drinks consumed in the year.

\section{Exposure variables:}

Parental supply: Children were asked about who supplied them alcohol (sips or whole drinks) in the past 12 months, including mother father, other adults, friends, siblings and self-supply. From this, a dichotomous exposure variable was coded indicating those who had received supply of alcohol from parental supply, and those who had not. For a secondary planned dose-response analysis, an exposure variable was coded into a measure of the number of years in which parental supply occurred (0, 1, 2, or 3) (see Statistical Analysis).

Other supply: Another exposure variable of "other supply" included supply from other adults, friends, siblings, or self-supply, compared to adolescents reporting no supply from these sources. Parental supply and other supply were not mutually exclusive, and as supply could be derived from both sources, each source was controlled for separately in analyses.

\section{Covariates:}

Covariates identified from the literature as associated with adolescent drinking were measured annually. These variables are fully described in supplementary material, and included: parental factors (alcohol use (Donovan and Molina, 2011, Swendsen et al., 2012), alcohol accessible at home without parental knowledge (Swendsen et al., 2012), alcohol-specific rules (Van Der Vorst et al., 2005, Van Der Vorst et al., 2007), monitoring (Swendsen et al., 2012), responsiveness/demandingness/consistency (Alati et al., 2010, Donovan and Molina, 2011), religiosity (Donovan and Molina, 2011)); family factors (one- or two-parent household (Alati et al., 2010), family conflict/positive relations (Ary et al., 1999), family alcohol problems (Kuperman et al., 2013), older siblings (Fisher et al., 2007)); child factors (sex, age in years, or part thereof, at time of survey completion (Fisher et al., 2007, Swendsen et al., 2012), money to purchase alcohol (Swendsen et al., 2012), tobacco use (Kuperman et al., 2013), externalising (Swendsen et al., 2012, Kuperman et al., 2013), internalising (Crum et al., 2008, Kuperman et 
al., 2013), problems socialising (Achenbach, 1991)); and peer factors (peer substance use, and peer disapproval of alcohol/tobacco use (Fisher et al., 2007, Swendsen et al., 2012, Kuperman et al., 2013)). Participants completed annual paper or online questionnaires, forwarded separately to adolescents and parents to minimise reporting biases. Data from 4 years (Waves 1 through 4 ) are included in this study.

\section{$\underline{\text { Statistical analysis }}$}

\section{Primary:}

Logistic regressions (random intercept mixed-effects model controlling for within-respondent and within-school clustering/correlation, and time) determined the relationship between parental supply and other supply and two outcomes: (a) drinking whole standard drinks; and (b) binge drinking, controlling for each source of supply and covariates and collinearity. Four years of data were analysed, with parental supply (yes/no) from each year used to model the two outcomes in the following years, while controlling for covariates (fully adjusted model). The analysis included paired time periods (period 1=Wave 1-2; period $2=$ Wave 2-3; period $3=$ Wave $3-4$ ), with exposures and covariates from each year predicting the outcomes in all the later years. Variables were included in adjusted analyses if they showed unadjusted significance at an alpha of 0.05 (five covariates were dropped).

\section{Secondary:}

Fixed-effect logistic regressions assessed for a dose-response between number of years in which parental supply occurred $(0,1,2$, or all 3 initial years $)$ and drinking outcomes in the fourth year. Analyses were also conducted using multiple imputation for missing data (eTable S1). Sensitivity analyses tested robustness of the dose-response relationship under three scenarios: (a) complete case analysis (no imputation); (b) all participants with missing outcomes coded as drinkers/bingers; and (c) all participants with missing outcomes coded as non-drinkers. Analyses 
used Stata 14.1 (Stata Corporation, 2012). Number of drinks consumed in the year and single occasion drinking rates were also examined using negative binomial regression (random intercept mixed-effects). Finally, potential moderating effects between parental supply and four other variables on the primary outcomes were investigated through analysis of interaction terms between parental supply and: child externalising, family history of alcohol problems, peer substance use, and peer disapproval of substance use. 


\section{Results}

\section{Sample drinking behaviour over time}

There was a steady increase in consumption of drinks and bingeing across the waves (Table 1).

Table 2 provides the sources and mean number of drinks/bingeing consumed by adolescent drinkers, separately for adolescents reporting any parental supply, and those reporting any other supply. Mean consumption was similar across supply source. The main sources of "other supply" were other adults and peers, and the frequency of supply from each "other supply" source is presented in Supplementary eTable S2.

\section{Unadjusted analyses}

Unadjusted, parental supply was strongly associated with both drinking whole standard drinks (odds ratio [OR] 5.71; 95\% CI 4.41-7.39) and, bingeing (OR 4.66; 95\% CI 3.48-6.24) (Table 3). Of the 30 variables analysed, the same six showed no significant unadjusted associations with drinking whole drinks, or bingeing: having older siblings; parent is Australian-born; parent education; parent employment; home access to alcohol; and family history of alcohol problems. These variables were not included in fully adjusted models.

\section{$\underline{\text { Adjusted analyses }}$}

Adjusting for other variables, we still found significant associations between parental supply and drinking whole drinks, but not with bingeing. Parental supply at any wave was associated with doubled odds of drinking at subsequent waves (OR 1.80; 95\% CI 1.33-2.45), but was not associated with bingeing (OR 1.12; 95\% CI 0.80-1.55). In contrast, other supply of alcohol from non-parental sources was associated with significant increased risk of both outcomes, unadjusted and adjusted. While supply from other sources was similarly associated with a doubling in the odds of drinking whole drinks (OR 2.53; 95\% CI 1.86-3.45), it was associated with a more than tripling in the odds of binge drinking (OR 3.51; 95\% CI 2.53-4.87) (Supplementary eTables S3 and S4). Consistent with this result, adolescents who received alcohol only from other supply sources, drank significantly more drinks than adolescents who were supplied alcohol only by 
their parents (and who were not supplied by other supply sources) $(\mathrm{F}=30.80 ; p<0.001)$.

Drinking and, bingeing were also associated with time, although in different ways. The odds of consuming whole drinks increased by around half in time period 2 (OR 1.45; 95\% CI 1.05-2.01), before increasing markedly in time period 3 (OR 4.75; 95\% CI 3.32-6.78) (Supplementary eTable S3). In contrast, binge drinking remained steady in time period 2 (OR 1.15; 95\% CI 0.791.67), but increased significantly in time period 3 (OR 3.13; 95\% CI 2.13-4.60) (Supplementary eTable S4).

Secondary analyses showed odds increasing with number of years of parental supply, consistent with a dose-response relationship, although the $95 \%$ CIs overlapped. There was an association ( $p=0.003$ ) between the number of waves of parental supply and drinking in Wave 4; those supplied alcohol even once by parents in any of Waves 1-3 were more likely to consume whole drinks in Wave 4 (OR 1.48; 95\% CI 1.03-2.12), and odds of consumption increased among those who were supplied alcohol in two years during Waves 1-3 (OR 1.92; 95\% CI 1.29-2.85), increasing further if supply occurred in all Waves 1-3 (OR 2.15; 95\% CI 1.21-3.82). Secondary analysis of number of waves of parental supply showed no dose-response relationship for bingeing (Supplementary eTable S5). Finally, the secondary analyses showed similar results for covariates as primary analyses, suggesting robust relationships.

\section{$\underline{\text { Sensitivity analyses }}$}

Analysis of the number of drinks consumed in the year showed a similar pattern to analysis of drinking whole drinks. Parental supply of alcohol was associated with a fourfold increase in the incidence-rate of number of drinks (Incidence-rate ratio [IRR] 3.68; 95\% CI 2.30-5.90) with a similar increase associated with other supply (IRR 2.67; 95\% CI 1.63-4.35) (Supplementary eTable S6). Number of drinks also showed a strong increase in the incidence-rate over time, doubling in time period 2 (IRR 2.35; 95\% CI 1.47-3.74), before a dramatic increase in time period 3 (IRR 10.70; 95\% CI 6.52-17.56). The sensitivity analysis of number of drinks 
consumed on a single typical drinking occasion (Supplementary eTable S7) supports the results of the model of binge drinking. Adolescents supplied alcohol by parents drank lower numbers of drinks on a typical occasion (IRR 0.89; 95\% CI 0.79-0.99) than those adolescents supplied only by other sources (i.e., other supply). The sensitivity analyses of the dose-response relationship found that relationship was maintained in complete case analysis. When more extreme assumptions were made, either assuming missing outcome data were all non-drinkers or all drinkers, the significant association with parental supply remained, although the pattern of odds ratios was less consistent with a dose-response relationship (Supplementary eTables S8-S10). Two additional post-hoc sensitivity analyses were also conducted. Firstly, to separate out the influence of sources of "other supply" on drinking behaviour, we conducted post-hoc analyses of the two primary outcomes with each source of "other supply" entered separately (i.e., other adults, siblings, peers, religious service, and self-supply). The only significant "other supply" sources predictive of drinking and/or bingeing were self-supply (OR 2.62; 95\% CI 1.71-4.03 and OR 3.16; 95\% CI 2.11-4.74 respectively) and peer-supply (OR 3.91; 95\% CI 2.16-7.08 and OR 2.64; $95 \%$ CI 1.56-4.49). Second, to eliminate the possibility that results were influenced by less common living arrangements, we re-conducted the primary analysis limiting the sample to adolescents who reported living in a two-parent mixed-gender (mother/father) household. A breakdown of adolescent rearing environment for each wave is presented in Supplementary eTable S11-12. The sensitivity analysis showed no substantive differences to the primary analysis.

\section{Moderating variables}

Analysis of potential moderating effects showed two significant interactions (of child externalising and peer substance use) with parental supply on the two outcomes. For both outcomes, the effect of parental supply was stronger with lower externalizing scores, with the effect declining as externalising score increased (Supplementary Figure S1). That is, if a child is 
higher on externalising, parental supply is less important to that child's drinking - externalisers seem more likely to seek out alcohol whether their parents supply or not. On the other hand, the interaction of parental supply and peer substance use showed a reversal in the direction of effect, with parental supply increasing the odds of drinking when low peer substance use was observed, but decreasing the odds when peer substance use was higher (Supplementary Figure S2). Family history of alcohol problems, and peer disapproval did not show any significant interaction effect.

\section{Discussion}

This first longitudinal study of associations between parental supply and other supply of alcohol and adolescent drinking, conducted over four years in a large representative cohort with excellent retention, comprehensively adjusted for known covariates (Kaynak et al., 2014). Before adjustment, parental supply of alcohol was associated with five-fold increased unadjusted odds of consuming whole drinks, consistent with earlier studies (Jackson et al., 1999, Komro et al., 2007, Shortt et al., 2007, Livingston et al., 2010, Van Der Vorst et al., 2010, Danielsson et al., 2011, McMorris et al., 2011). Also, there were increased unadjusted odds of bingeing among adolescents supplied alcohol by parents. In adjusted longitudinal mixed-model analyses which: (a) controlled for familial/adolescent/peer characteristics in each wave being interrelated, (b) assessed parental supply controlling for growth in drinking rates over time, and (c) included variables with significant unadjusted associations, parental supply was still associated with a doubling of the odds of drinking, but no longer associated with bingeing. Our results are consistent with the results of studies that consistently find increased drinking, but not necessarily increased heavy episodic drinking (Kaynak et al., 2014). We also found adolescents supplied alcohol by parents drank less on a typical drinking occasion than adolescents supplied alcohol from other sources (and not from their parents), as some others also report (Foley et al., 2004, Bellis et al., 2007, Dietze and Livingston, 2010), possibly due to the supervisory nature where 
there is parental presence. In this last regard, it is likely that the drinking context matters, as do child perceptions of parental permissiveness, issues which we are pursuing in this cohort. There was no evidence of over-adjustment or collinearity affecting these results.

As expected from other research (Alati et al., 2005, Fisher et al., 2007, Donovan and Molina, 2011, Kuperman et al., 2013), we also detected some variables associated with lower odds of drinking, specifically: parental monitoring, responsive and consistent parenting, religiosity, child social problems, and peer disapproval of substance use (Supplementary eTables S3). Increased odds of drinking were observed for: peer substance use and child externalising. Turning to bingeing, odds were decreased by: alcohol-specific rules; responsive and consistent parenting, religiosity, and peer disapproval of substance use. Externalising was associated with increased odds of bingeing, as reported elsewhere (Swendsen et al., 2012, Kuperman et al., 2013).

Our results also showed a dose-response relationship: adolescents supplied alcohol by parents in the one, two, or in all three initial years, were increasingly more likely to drink whole beverages in year 4. Sensitivity analyses showed this relationship was robust when only complete cases were analysed, and also when missing responses were classified as non-drinkers. Interestingly, being supplied alcohol from other sources increased the odds of both drinking and bingeing. It thus seems that while both parental supply and other supply were equally related to drinking, only other supply - but not parental supply - was more likely to be associated with bingeing. Findings from these mixed-effect regressions were replicated in fixed-effect logistic regression analyses, indicating robust results, confirming relationships reported in cross-sectional studies (Foley et al., 2004, Bellis et al., 2007, Dietze and Livingston, 2010). Notably, given no other cohort studies control for other supply, associations of parental supply with drinking in those studies may be inflated. This is an important point, as causality is often inferred via associations. 
Our study has limitations. First, IRB approval allowed information about the study to be available through classrooms, but families had to opt-in, so the self-selected sample restricts generalisations to the population, and reporting biases may underestimate population rates of alcohol consumption (Stockwell et al., 2004). However, our child and parent drinking rates were very similar to those in population surveys (Australian Institute of Health \& Welfare, 2011, White and Bariola, 2012, Wadolowski et al., 2015), and the sample closely matches the Australian population in sex, age, household composition, and SES. Additionally with regard to bias, we aimed to assess associations between exposures and outcomes, where population representativeness is less crucial. These observations suggest selective responding and reporting may not have substantially affected the alcohol estimates and associations herein. Second, the legal age to purchase alcohol in Australia is 18 years (parents may legally provide alcohol to children), so generalisations to other cultures should be considered carefully, although there is evidence of some cross-country similarities (McMorris et al., 2011). Third, the cohort is too young to show development of alcohol-use disorders (Hingson et al., 2006), so we cannot assess long-term harms (Gore et al., 2011, Patton et al., 2012). Fourth, we have not explored associations between either amounts (sips versus drinks) or settings (supervised versus unsupervised) of parental supply and adolescent consumption. Such analyses between drinking and the amounts/frequency and settings of parental supply, or indeed the specific sources of other supply (Samek et al., 2015), are beyond our scope here, but need to be undertaken. Fifth, we do not address population trends over time (Keyes et al., 2012), advertising, or environmental/regulatory factors (Moreno et al., 2011, Tanski et al., 2015).

While we report associations, the findings do strongly suggest the potential for parental supply to accelerate adolescent alcohol consumption, compared to no supply, consistent with conclusions by others (Kaynak et al., 2014). This possibility is concerning given adolescent vulnerabilities to the effects of alcohol (Brown et al., 2008), and associations with adverse adult outcomes (Patton 
et al., 2012). However, while adolescents supplied alcohol by parents were more likely to drink than those not supplied, parental supply was not associated with increased bingeing. This finding was supported by less alcohol being consumed on a typical drinking occasion by adolescents who have been supplied by parents, compared to those accessing alcohol from other sources (controlling for each source in the analyses). Also, in contrast and somewhat surprisingly other supply was associated with increased odds of bingeing after adjustment.

There are several possible explanations for the pattern of findings. Given that parental supply increases the odds of drinking, but not of bingeing, parental supply may have a protective effect, possibly due to the supervised nature of the supply. However, our view is that such a conclusion is premature at this time. These results should not be taken to suggest that parental supply is somehow protective of bingeing in the longer-term. In fact, parents may be accelerating children into drinking alcohol, and laying down the potential for later harms (Shaffer et al., 2000, Hingson et al., 2006, Jackson et al., 2012, Patton et al., 2012). It is possible that parents supplying alcohol to their children are setting up a pattern of drinking; higher frequency but lower volume than those supplied by others. Parental supply of alcohol may ultimately signify permissiveness to children, and while only other supply was associated with bingeing in this study, the patterns of use may alter as these children grow older. Further investigation of the patterns of use in adolescence and in early adulthood is needed. The significant interaction effect of child externalising behaviour further adds to the complexity of the findings; depending on the children themselves, the impact of parental supply of alcohol is likely to be different. While these parents may be supplying alcohol as an attempt to moderate their child's drinking, or because they believe their child will receive alcohol from their peers anyway, as we have found in this cohort (Wadolowski et al., 2016), it seems that children high on externalising are less influenced by parental supply and seem likely to obtain alcohol whether their parents supply or not. 
This is clearly a highly complex area and one that has significant relevance to public and mental health professionals and policymakers, and parents, as understanding these relationships can alter professional opinion, parental and child behaviour. The results have international relevance as alcohol use increases with the growth in wealth of developing economies whose populations embrace western habits (Jiang et al., 2015). Given that the findings here are limited to drinking between early and mid-teen years, further study of the cohort is essential to understand the longer-term relationships between parental supply and early adult alcohol use and bingeing.

The questions are clear. Does parental supply protect in the short-term and set-up patterns of moderate (non-binge) drinking into adulthood, or lead to heavier drinking when adolescents are of a legal age to drink? This is the issue that is central to our work - does parental supply harm or help. A precautionary principle remains appropriate for parents to ensure that early drinking does not compromise child well-being (Furtner and Rivara, 2011). Follow-up of this cohort into adulthood will help clarify impacts of early drinking on more mature consumption patterns. 


\section{$\underline{\text { References }}$}

Achenbach, T. M. (1991). Manual for the youth self-report and 1991 profile, Burlington, University of Vermont.

Aiken, A., Wadolowski, M., Bruno, R., Najman, J., Kypri, K., Slade, T., Hutchinson, D., Mcbride, N. \& Mattick, R. P. (2015). Cohort profile: The Australian Parental Supply of Alcohol Longitudinal Study (APSALS). International Journal of Epidemiology, 1-11.

Ajzen, I. (2002). Perceived behavioral control, self-efficacy, locus of control, and the theory of planned behavior. Journal of Applied Psychology, 32, 665-683.

Alati, R., Maloney, E., Hutchinson, D. M., Najman, J. M., Mattick, R. P., Bor, W. \& Williams, G. M. (2010). Do maternal parenting practices predict problematic patterns of adolescent alcohol consumption? Addiction, 105, 872-880.

Alati, R., Najman, J. M., Kinner, S. A., Mamun, A. A., Williams, G. M., O'callaghan, M. \& Bor, W. (2005). Early predictors of adult drinking: A birth cohort study. American Journal of Epidemiology, 162, 1098-1107.

Ary, D. V., Duncan, T. E., Duncan, S. C. \& Hops, H. (1999). Adolescent problem behavior: The influence of parents and peers. Behaviour Research \& Therapy, 37.

Australian Institute of Health \& Welfare (2011). 2010 National Drug Strategy Household Survey report. In: Australian Institute of Health \& Welfare (ed.). Canberra: Australian Institute of Health \& Welfare.

Barnes, G. M., Reifman, A. S., Farrell, M. P. \& Dintcheff, B. A. (2000). The effects of parenting on the development of adolescent alcohol Misuse: A six-wave latent growth model. Journal of Marriage and Family, 62, 175-186.

Bellis, M. A., Hughes, K., Morleo, M., Tocque, K., Hughes, S., Allen, T., Harrison, D. \& FeRodriguez, E. (2007). Predictors of risky alcohol consumption in schoolchildren and their implications for preventing alcohol-related harm. Subst Abuse Treat Prev Policy, 2, 15. 
Borsari, B. \& Carey, K. B. (2001). Peer influences on college drinking: A review of the research. Journal of Substance Abuse, 13, 391-424.

Brown, S. A., Mcgue, M., Maggs, J., Schulenberg, J., Hingson, R., Swartzwelder, S., Martin, C., Chung, T., Tapert, S. F., Sher, K., Winters, K. C., Lowman, C. \& Murphy, S. (2008). A developmental perspective on alcohol and youths 16 to 20 years of age. Pediatrics, 121 , S290-S310.

Bush, K., Kivlahan, D. R., Mcdonell, M. B., Fihn, S. D. \& Bradley, K. A. (1998). The AUDIT alcohol consumption questions (AUDIT-C): An effective brief screening test for problem drinking. Archives of Internal Medicine, 158.

Crum, R. M., Green, K. M., Storr, C. L., Chan, Y. F., Ialongo, N., Stuart, E. \& Anthony, J. C. (2008). Depressed mood in childhood and subsequent alcohol use through adolescence and young adulthood. Archives of General Psychiatry, 65, 702-712.

Danielsson, A.-K., Romelsjö, A. \& Tengström, A. (2011). Heavy episodic drinking in early adolescence: Gender-specific risk and protective factors. Substance Use \& Misuse, 46, 633-643.

Diclemente, R. J., Wingood, G. M., Crosby, R., Sionean, C., Cobb, B. K., Harrington, K., Davies, S., Hook, E. W. \& Oh, M. K. (2001). Parental monitoring: Association with adolescents' risk behaviors. Pediatrics, 107, 1363-1368.

Dietze, P. M. \& Livingston, M. (2010). The relationship between alcohol supply source and young people's risky drinking and alcohol-related problem behaviours. Aust N Z J Public Health, 34, 364-7.

Donovan, J. E. \& Molina, B. S. G. (2008). Children's introduction to alcohol use: Sips and tastes. Alcoholism: Clinical \& Experimental Research, 32, 108-119.

Donovan, J. E. \& Molina, B. S. G. (2011). Childhood risk factors for early-onset drinking. Journal of Studies on Alcohol \& Drugs, 72, 741-751. 
Fisher, L. B., Miles, I., Austin, S., Camargo, C. A. \& Colditz Jr, G. A. (2007). Predictors of initiation of alcohol use among US adolescents: Findings from a prospective cohort study. Archives of Pediatrics and Adolescent Medicine, 161, 959-966.

Foley, K. L., Altman, D., Durant, R. H. \& Wolfson, M. (2004). Adults' approval and adolescents' alcohol use. Journal of Adolescent Health, 34, 345.

Furtner, F. \& Rivara, F. P. (2011). Preventing and treating adolescent alcohol use. Archives of Pediatrics \& Adolescent Medicine, 165, 284-284.

Gilligan, C., Kypri, K. \& Lubman, D. (2012). Changing parental behaviour to reduce risky drinking among adolescents: Current evidence and future directions. Alcohol and alcoholism, 47, 349-354.

Gore, F. M., Bloem, P. J. N., Patton, G. C., Ferguson, J., Joseph, V., Coffey, C., Sawyer, S. M. \& Mathers, C. D. (2011). Global burden of disease in young people aged 10-24 years: A systematic analysis. The Lancet, 377, 2093-2102.

Hearst, M. O., Fulkerson, J. A., Maldonado-Molina, M. M., Perry, C. L. \& Komro, K. A. (2007). Who needs liquor stores when parents will do? The importance of social sources of alcohol among young urban teens. Preventive Medicine, 44, 471-476.

Henderson, H., Nass, L., Payne, C., Phelps, A. \& Ryley, A. (2013). Smoking, drinking and drug use among young people in England in 2012. In: Henderson, H., Nass, L., Payne, C., Phelps, A. \& Ryley, A. (eds.). London: NHS Information Centre for Health \& Social Care.

Hingson, R. W., Heeren, T. \& Winter, M. R. (2006). Age at drinking onset and alcohol dependence: Age at onset, duration, and severity. Archives of Pediatrics \& Adolescent Medicine, 160, 739-746.

Jackson, C., Ennett, S. T., Dickinson, D. M. \& Bowling, J. (2012). Letting children sip: Understanding why parents allow alcohol use by elementary school-aged children. Archives of Pediatrics \& Adolescent Medicine, 166, 1053-1057. 
Jackson, C., Henriksen, L. \& Dickinson, D. M. (1999). Alcohol-specific socialization, parenting behaviors and alcohol use by children. Journal of Studies on Alcohol and Drugs, 60, 362367.

Jiang, H., Room, R. \& Hao, W. (2015). Alcohol and related health issues in China: Action needed. The Lancet Global Health, 3, e190-e191.

Kaynak, Ö., Winters, K. C., Cacciola, J., Kirby, K. C. \& Arria, A. M. (2014). Providing alcohol for underage youth: What messages should we be sending parents? Journal of Studies on Alcohol and Drugs, 75, 590-605.

Keyes, K. M., Schulenberg, J. E., O'malley, P. M. \& Et Al. (2012). Birth cohort effects on adolescent alcohol use: The influence of social norms from 1976 to 2007. Archives of General Psychiatry, 69, 1304-1313.

Komro, K. A., Maldonado-Molina, M. M., Tobler, A. L., Bonds, J. R. \& Muller, K. E. (2007). Effects of home access and availability of alcohol on young adolescents' alcohol use. Addiction, 102.

Kuperman, S., Chan, G., Kramer, J. R., Wetherill, L., Bucholz, K. K., Dick, D., Hesselbrock, V., Porjesz, B., Rangaswamy, M. \& Schuckit, M. (2013). A model to determine the likely age of an adolescent's first drink of alcohol. Pediatrics, 131, 242-248.

Livingston, J. A., Testa, M., Hoffman, J. H. \& Windle, M. (2010). Can parents prevent heavy episodic drinking by allowing teens to drink at home? Addictive Behaviors, 35, 1105 1112.

Mccambridge, J., Mcalaney, J. \& Rowe, R. (2011). Adult consequences of late adolescent alcohol consumption: A systematic review of cohort studies. PLoS Med, 8, e1000413.

Mcmorris, B. J., Catalano, R. F., Kim, M. J., Toumbourou, J. W. \& Hemphill, S. A. (2011). Influence of family factors and supervised alcohol use on adolescent alcohol use and harms: Similarities between youth in different alcohol policy contexts. J Stud Alcohol Drugs, 72, 418-28. 
Moreno, M. A., Furtner, F. \& Rivara, F. P. (2011). Media influence on adolescent alcohol use. Archives of Pediatrics \& Adolescent Medicine, 165, 680-680.

Nash, S. G., Mcqueen, A. \& Bray, J. H. (2005). Pathways to adolescent alcohol use: Family environment, peer influence, and parental expectations. Journal of Adolescent Health, 37, $19-28$.

National Health \& Medical Research Council (2009). Australian guidelines to reduce health risks from drinking alcohol. In: National Health \& Medical Research Council (ed.). Canberra: Commonwealth of Australia.

Oetting, E. R. \& Donnermeyer, J. F. (1998). Primary socialization theory: The etiology of drug use and deviance. I. Substance Use \& Misuse, 33, 995-1026.

Patton, G. C., Coffey, C., Cappa, C., Currie, D., Riley, L., Gore, F., Degenhardt, L., Richardson, D., Astone, N., Sangowawa, A. O., Mokdad, A. \& Ferguson, J. (2012). Health of the world's adolescents: A synthesis of internationally comparable data. The Lancet, 379, 1665-1675.

Pennay, A., Livingston, M. \& Maclean, S. (2015). Young people are drinking less: It is time to find out why. Drug and Alcohol Review, 34, 115-118.

Real, K. \& Rimal, R. N. (2007). Friends talk to friends about drinking: Exploring the role of peer communication in the theory of normative social behavior. Health Communication, 22, 169-180.

Rossow, I., Keating, P., Felix, L. \& Mccambridge, J. (2015). Does parental drinking influence children's drinking? A systematic review of prospective cohort studies. Addiction.

Samek, D. R., Mcgue, M., Keyes, M. \& Iacono, W. G. (2015). Sibling facilitation mediates the association between older and younger sibling alcohol use in late adolescence. Journal of Research on Adolescence, 25, 638-651.

Shaffer, D., Fisher, P., Lucas, C. P., Dulcan, M. K. \& Schwab-Stone, M. E. (2000). NIMH Diagnostic Interview Schedule for Children Version IV (NIMH DISC-IV): Description, 
Differences From Previous Versions, and Reliability of Some Common Diagnoses. Journal of the American Academy of Child \& Adolescent Psychiatry, 39, 28-38.

Shortt, A. L., Hutchinson, D. M., Chapman, R. \& Toumbourou, J. W. (2007). Family, school, peer and individual influences on early adolescent alcohol use: First-year impact of the resilient families programme. Drug and Alcohol Review, 26, 625-634.

Stata Corporation (2012). Stata/SE 11.2 for Windows. College Station, Texas: StataCorp LP.

Stockwell, T., Donath, S., Cooper-Stanbury, M., Chikritzhs, T., Catalano, P. \& Mateo, C. (2004). Under-reporting of alcohol consumption in household surveys: A comparison of quantity-frequency, graduated-frequency and recent recall. Addiction, 99, 1024-1033.

Swendsen, J., Burstein, M., Case, B., Conway, K. P., Dierker, L., He, J. \& Merikangas, K. R. (2012). Use and abuse of alcohol and illicit drugs in US adolescents: Results of the National Comorbidity Survey-Adolescent Supplement. Archives of General Psychiatry, 69, 390-398.

Tanski, S. E., Mcclure, A. C., Li, Z. \& Et Al. (2015). Cued recall of alcohol advertising on television and underage drinking behavior. JAMA Pediatrics, 169, 264-271.

Van Der Vorst, H., Engels, R. C. M. E. \& Burk, W. J. (2010). Do parents and best friends influence the normative increase in adolescents' alcohol use at home and outside the home? Journal of Studies on Alcohol and Drugs, 71, 105-114.

Van Der Vorst, H., Engels, R. C. M. E., Deković, M., Meeus, W. \& Vermulst, A. A. (2007). Alcohol-specific rules, personality and adolescents' alcohol use: A longitudinal personenvironment study. Addiction, 102, 1064-1075.

Van Der Vorst, H., Engels, R. C. M. E., Meeus, W., Dekovic, M. \& Van Leeuwe, J. (2005). The role of alcohol-specific socialization in adolescents' drinking behaviour. Addiction Biology, 100, 1464-1476.

Von Elm, E., Altman, D., Egger, M., Pocock, S., Gøtzsche, P., Vandenbroucke, J. \& Strobe Initiative (2007). The Strengthening the Reporting of Observational Studies in 
Epidemiology (STROBE) statement: Guidelines for reporting observational studies. Lancet, 370, 1453-1457.

Wadolowski, M., Bruno, R., Aiken, A., Stone, C., Najman, J., Kypri, K., Slade, T., Hutchinson, D., Mcbride, N. \& Mattick, R. P. (2015). Sipping, drinking, and early adolescent alcohol consumption: A cautionary note. Alcoholism: Clinical and Experimental Research, 39, $350-354$.

Wadolowski, M., Hutchinson, D., Bruno, R., Aiken, A., Najman, J., Kypri, K., Slade, T., Mcbride, N. \& Mattick, R. P. (2016). Parents who supply alcohol in early adolescence: A prospective study of risk factors. Pediatrics, 137.

White, V. \& Bariola, E. (2012). Australian secondary school students' use of tobacco, alcohol, and over-the-counter and illicit substances in 2011. In: White, V. \& Bariola, E. (eds.). Victoria: Centre for Behavioural Research in Cancer, The Cancer Council Victoria.

Zernicke, K. A., Cantrell, H., Finn, P. R. \& Lucas, J. (2010). The association between earlier age of first drink, disinhibited personality, and externalizing psychopathology in young adults. Addictive Behaviors, 35, 414-418. 
Table 1. Adolescent drinking and binge drinking rates and percentages at each measurement wave

Annual assessment wave

School Grade

(N = number of respondents with valid data)

Wave 1

School Grade 7 $(\mathbf{N}=1911)$

\section{Wave 2}

School Grade

$(\mathrm{N}=\mathbf{1 8 3 7})$

$111(5.8 \%)$

$150(8.2 \%)$

$101(5.5 \%)$

hool Grade 9 ( $N=$ 1786)

Whole (standard) drink(s) consumption: n (\%)

Wave 4

School Grade 10 $(\mathrm{N}=\mathbf{1 7 0 6})$

$498(29.2 \%)$

Binge drinking ( $\geq 4$ standard drinks on an occasion): $\mathrm{n}(\%)$
$26(1.4 \%)$

Students were a mean age of 12.9 years at Wave $1 . \mathrm{N}=$ number of respondents with valid data. $\mathrm{n}=$ number of participants reporting the behaviour at each measurement wave. 
Percentage of adolescents reporting no supply of alcohol and those receiving alcohol from parental supply, other supply, or from both sources (n of participants at each Wave)

\begin{tabular}{|c|c|c|c|c|}
\hline Source(s) of supply of alcohol (sips or whole standard drinks) & $\begin{array}{c}\text { Wave 1 } \\
(n=1911)\end{array}$ & $\begin{array}{c}\text { Wave 2 } \\
(n=1837)\end{array}$ & $\begin{array}{c}\text { Wave } 3 \\
(n=1786)\end{array}$ & $\begin{array}{c}\text { Wave } 4 \\
(n=1706)\end{array}$ \\
\hline No alcohol was reported as being supplied from any source & $81.5 \%$ & $67.5 \%$ & $62.0 \%$ & $51.6 \%$ \\
\hline Parental supply only was reported (and no other supply source) & $9.3 \%$ & $13.1 \%$ & $11.9 \%$ & $10.5 \%$ \\
\hline Other supply only was reported (and no parental supply source) & $3.3 \%$ & $6.9 \%$ & $10.8 \%$ & $14.2 \%$ \\
\hline Both parental supply and other supply were reported & $6.0 \%$ & $12.6 \%$ & $15.3 \%$ & $23.7 \%$ \\
\hline
\end{tabular}

Drinking of whole standard drinks and bingeing behaviours among those who were supplied alcohol (n of participants consuming whole standard drinks at each Wave)

\begin{tabular}{|c|c|c|c|c|c|}
\hline & & $\begin{array}{l}\text { Wave 1 } \\
(n=111)\end{array}$ & $\begin{array}{l}\text { Wave } 2 \\
(n=150)\end{array}$ & $\begin{array}{l}\text { Wave 3 } \\
(n=267) \\
\end{array}$ & $\begin{array}{l}\text { Wave } 4 \\
(n=498)\end{array}$ \\
\hline $\begin{array}{l}\text { Any } \\
\text { Parental }\end{array}$ & Mean (sd) no. of standard drinks consumed p.a. & $52.7(98.3)$ & $157.9(461.8)$ & $139.2(425.8)$ & $139.0(508.7)$ \\
\hline $\begin{array}{l}\text { supply } \\
\text { occurred in } \\
\text { the wave } \mathrm{e}^{\mathrm{a}}\end{array}$ & No. of drinkers/No. of drinkers who binged & $\begin{array}{c}67 \text { drank/15 drinkers } \\
\text { binged }\end{array}$ & $\begin{array}{c}86 \text { drank/62 drinkers } \\
\text { binged }\end{array}$ & $\begin{array}{c}156 \text { drank/92 drinkers } \\
\text { binged }\end{array}$ & $\begin{array}{l}315 \text { drank/208 } \\
\text { drinkers binged }\end{array}$ \\
\hline Any Other & Mean (sd) no. of standard drinks consumed p.a. & $51.8(96.3)$ & $165.2(438.6)$ & $132.9(366.0)$ & $126.0(445.1)$ \\
\hline $\begin{array}{l}\text { occurred in } \\
\text { the wave }^{\mathrm{a}}\end{array}$ & No. of drinkers/No. who of drinkers binged & $\begin{array}{c}70 \text { drank/22 drinkers } \\
\text { binged }\end{array}$ & $\begin{array}{c}131 \text { drank/92 drinkers } \\
\text { binged }\end{array}$ & $\begin{array}{l}229 \text { drank/158 } \\
\text { drinkers binged }\end{array}$ & $\begin{array}{c}435 \text { drank/304 } \\
\text { drinkers binged }\end{array}$ \\
\hline
\end{tabular}

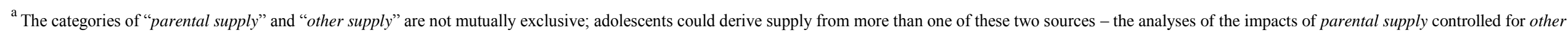

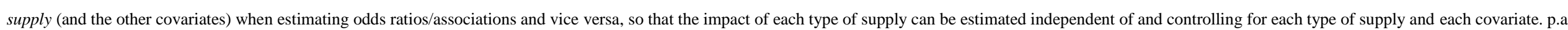
refers to per annum. Bingeing is defined as $\geq 5$ standard drinks on an occasion. 
Table 3. Odds ratios (OR) and $95 \%$ CIs for associations of source of supply at current wave, and subsequent wave drinking of whole beverages and binge drinking

\begin{tabular}{|c|c|c|c|c|c|c|c|c|c|}
\hline \multirow{3}{*}{ Variables } & & \multicolumn{4}{|c|}{ Odds of drinking whole drinks ${ }^{\mathrm{a}}$} & \multicolumn{4}{|c|}{ Odds of binge drinking $^{\mathrm{a}}$} \\
\hline & & \multicolumn{2}{|c|}{ Unadjusted odds ratios } & \multicolumn{2}{|c|}{ Adjusted odds ratios ${ }^{b}$} & \multicolumn{2}{|c|}{ Unadjusted odds ratios } & \multicolumn{2}{|c|}{ Adjusted odds ratios ${ }^{b}$} \\
\hline & & OR; $95 \%$ CI & $p$-value & OR; $95 \%$ CI & $p$-value & OR; $95 \%$ CI & $p$-value & OR; $95 \%$ CI & $p$-value \\
\hline \multirow{2}{*}{$\begin{array}{l}\text { Current wave parental } \\
\text { supply }\end{array}$} & No & 1.00 & & 1.00 & & 1.00 & & 1.00 & \\
\hline & Yes & $\begin{array}{l}5.71 ; \\
4.41-7.39\end{array}$ & $p<0.001$ & $\begin{array}{l}1.80 ; \\
1.33-2.45\end{array}$ & $p<0.001$ & $\begin{array}{l}4.66 ; \\
3.48-6.24\end{array}$ & $p<0.001$ & $\begin{array}{l}1.12 ; \\
0.80-1.55\end{array}$ & $p=0.518$ \\
\hline \multirow{2}{*}{$\begin{array}{l}\text { Current wave other } \\
\text { supply }^{c}\end{array}$} & No & 1.00 & & 1.00 & & 1.00 & & 1.00 & \\
\hline & Yes & $\begin{array}{l}12.73 \\
10.01-16.19\end{array}$ & $p<0.001$ & $\begin{array}{l}2.53 ; \\
1.86-3.45\end{array}$ & $p<0.001$ & $\begin{array}{l}15.39 ; \\
11.66-20.32\end{array}$ & $p<0.001$ & $\begin{array}{l}3.51 ; \\
2.53-4.87\end{array}$ & $p<0.001$ \\
\hline
\end{tabular}

${ }^{a}$ Results of random intercept mixed-effects logistic regression models. Data included as paired waves, with covariates from one wave and outcome from subsequent wave. Significant random effects were observed for the multivariate logistic mixed model of drinking whole drinks (School intercept SD: 0.37; ID intercept SD: 1.54; p<0.001) and binge drinking (School intercept SD: 0.38; ID intercept SD: 1.45; p<0.001).

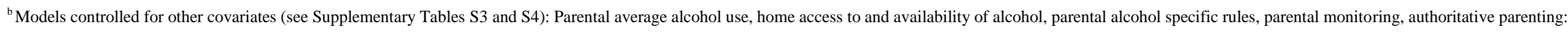

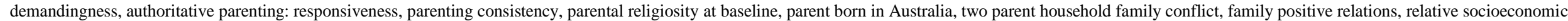

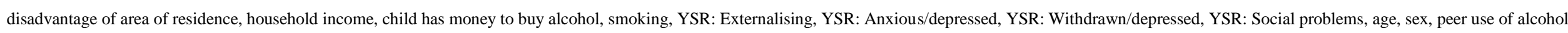
and/or tobacco, peer disapproval of alcohol and/or tobacco use.

'Included here was alcohol supply from: a family friend or relative or adult; a brother/sister; friends; or alcohol received as part of religious service; or alcohol where "I got it myself". 


\title{
Supplementary material for the article:
}

\section{Parental supply of alcohol and alcohol consumption in adolescence: Prospective cohort study}

\author{
Authors \\ Email: r.mattick@unsw·edu·au \\ Dr Monika Wadolowski, PhD ${ }^{1}$ \\ Ms Alexandra Aiken, BPsych (Hons) ${ }^{1}$ \\ Mr Philip Clare, MBiostats ${ }^{2}$ \\ Dr Delyse Hutchinson, $\mathrm{PhD}^{3}$ \\ Prof Jackob Najman, $\mathrm{PhD}^{4}$ \\ A/Prof Tim Slade, $\mathrm{PhD}^{1}$ \\ A/Prof Raimondo Bruno, $\mathrm{PhD}^{5}$ \\ Dr Nyanda McBride, $\mathrm{PhD}^{6}$ \\ Prof Louisa Degenhardt, $\mathrm{PhD}{ }^{1}$ \\ Prof Kypros Kypri, $\mathrm{PhD}^{7}$
}

Prof Richard P Mattick, $\mathrm{PhD}^{1}$ (Corresponding author*)

Telephone: +61293850331 Fax: +61293850222

$1 \quad$ National Drug \& Alcohol Research Centre, University of New South Wales (UNSW) Australia, Sydney NSW 2052 Australia;

2 The Kirby Insitute, University of New South Wales (UNSW) Australia, Sydney NSW 2052 Australia;

3 School of Psychology, Deakin University, Melbourne VIC 3125 Australia;

4 Queensland Alcohol and Drug Research and Education Centre, University of Queensland, Brisbane QLD 4072

Australia;

5 School of Psychology, University of Tasmania, Hobart TAS 7000 Australia;

$6 \quad$ National Drug Research Institute, Curtin University, GPO Box U1987, Perth WA 6845 Australia;

7 Centre for Clinical Epidemiology and Biostatistics, School of Medicine and Public Health, University of Newcastle, Newcastle NSW 2308 Australia.

Correspondence to:

Professor Richard P Mattick, NHMRC Principal Research Fellow, National Drug and Alcohol Research Centre,

Longitudinal Cohorts Research Consortium, UNSW Australia, Sydney, NSW, 2052, Australia r·mattick@unsw·edu·au

This material supplements but does not replace the peer-reviewed article entitled: 'Parental supply of alcohol and alcohol consumption in adolescence: Prospective cohort study' 


\section{Description of adolescent-report and parent-report measures}

\section{OUTCOME MEASURES}

\section{Adolescent consumption of whole drinks}

Frequency of drinking whole drinks

This item was adapted from the 2007 Australian National Drug Strategy Household Survey (NDSHS), asking how often alcohol was consumed in the past 12-months.(Australian Institute of Health \& Welfare, 2008) There were seven response options, ranging between less often, about one day a month, and every day. An additional response of never was included. Responses were collapsed into a binary variable of never versus any frequency of consumption of whole drinks in the past 12-months.

\section{Adolescent binge drinking}

This was also adapted from the NDSHS survey,(Australian Institute of Health \& Welfare, 2008) asking adolescents how often they consumed more than four standard drinks on a single occasion in the past 12-months. There were seven response options, ranging between never, less often, about one day a month through to every day. These responses were collapsed into a binary variable of never versus any frequency of binge drinking in the past 12-months.

\section{EXPOSURE MEASURE}

\section{Supply of alcohol by parents, and other sources}

Adolescents were asked about the quantity of alcohol supplied by their mothers and fathers (Parental supply), and family friend/relative/other adult, brother or sister, friends, as part of a religious service, and themselves (Other supply). There were six response options ranging between: none, sip or taste, 1 drink, 2 drinks, 3-4 drinks, or 5 or more drinks. These categories were collapsed to create a binary exposure variable: not supplied (none) versus supplied (sip or taste, 1 drink, 2 drinks, 3-4 drinks, or 5 or more drinks).

\section{PREDICTOR MEASURES}

\section{Child and parent demographics}

Child age and sex, whether parents were born in Australia, relative socioeconomic disadvantage of area of residence, parent education, parental employment status, and family income were measured at Wave 1. Age was included as a continuous variable, based on the child's age in years (with months and days decimalised) at the time of survey completion.

\section{Time}

For the primary analyses, three paired time points were used in the model, with covariates from one wave predicting the outcome from the next (time period $1=$ Wave $1-2$, time period $2=$ Wave $2-3$, time period $3=$ Wave $3-4$ ). The exception being a small number of time-invariant covariates (for example, sex), for which the baseline value was included. These time-invariant covariates are noted in the relevant tables.

In contrast, the secondary analyses used data from Waves one, two and three to predict the outcomes in Wave four, with covariates largely taken from Wave 3, in order to match the analyses more closely to the primary analyses, with the exception of parental supply, other supply and smoking (which were combined across Waves 1-3), and a small number of variables which were only measured in Wave 1 . The wave variables were taken from is noted in the relevant tables.

\section{Parent predictors}

\section{Parental alcohol use}

A score for total parental alcohol use was calculated using a quantity*frequency measure derived from items in the NDSHS.(Australian Institute of Health \& Welfare, 2008) In Wave 1, we gathered only the responding parent's report of consumption, and thereafter we gathered both parents consumption, and averaged the two amounts of consumption, yielding an averaged parental consumption for waves after Wave 1.

Parents were asked how many standard drinks they usually consumed in the past 12-months, with six response options ranging between 1-2 drinks and 13 or more drinks. Quantity was given a numeric score representing the number of standard drinks indicated by the category, or if the category contained a range, the midpoint of the group (None $=0$, A sip or taste $=0 \cdot 1$ (a sip estimated to be $10 \%$ of a standard drink), $1-2$ drinks $=1 \cdot 5,3-4$ drinks $=3 \cdot 5,5-6$ drinks $=5 \cdot 5,7-10$ drinks $=8 \cdot 5,11-12$ drinks $=11 \cdot 5$, and 13 or more drinks $=13$ ).

For frequency, parents were asked how often they consumed alcohol in the past 12-months, with seven response options ranging between less often (than monthly), and every day. Frequency was then given a numeric score representing the yearly frequency of the categorical group or if the group included a range of frequencies, the midpoint of the group (Never $=0$, less often than once a month $=5 \cdot 5$ (midpoint of 11 times per year), once per month=12, 2-3 days $/ \mathrm{month}=30,1$ 2 days/week=78, 3-4 days/week=182, 5-6 days/week=286, and everyday=365). The quantity and frequency scores were multiplied to give a total score representing the number of standard drinks consumed per year. 


\section{Home access to, and availability of, alcohol}

Access to alcohol in the family home was assessed with a six-item scale, which has previously been found to have acceptable internal consistency (Cronbach's alpha=0.76).(Komro et al., 2007) Items included: "do you keep track of the alcohol supply in your home?" and "how likely do you think it is that your child would have taken alcohol from your home without you knowing?". Higher scores indicated increased levels of access to alcohol in the family home (score range: 6-20).

\section{Parental alcohol-specific rules}

A 10-item scale developed in the Netherlands assessed alcohol-specific rules, as reported by children.(van der Vorst et al., 2005) Excellent internal consistency has previously been reported for this scale in an early adolescent sample (M age: 13; Cronbach's alpha=0.92). The 10 items were: 1) "I am allowed to drink alcohol at home when my father or mother is around"; 2) "I am allowed to drink alcohol at home when my father or mother is not around"; 3) "I am allowed to drink more than one glass of alcohol at home when my mother or father is around"; 4) "I am allowed to drink more than one glass of alcohol at home when my mother or father is not around"; 5) "I am allowed to drink as much alcohol as I'd like outside the house"; 6) "I am allowed to drink alcohol with my friends at a party"; 7) "I am allowed to come home drunk"; 8) "I am allowed to become drunk when I go out with my friends"; 9) "I am allowed to drink alcohol on the weekend"; and 10) I am allowed to drink alcohol during the week". Responses were summed, with a higher score indicating stricter alcohol-specific rules (score range: 10-50).

\section{Parental monitoring}

A widely used six-item child-report scale with good internal consistency (Cronbach's alpha=0 87 ) assessed parental monitoring.(Small and Kerns, 1993) Items included: "My parent(s) usually know what I am doing after school"; and "I talk to my parent(s) about the plans I have with friends". Each item had five response options: never to always.

Responses were summed, with a higher score indicating stricter monitoring (score range: 6-30).

\section{Parental responsiveness/demandingness}

The Authoritative Parenting Index measured parental responsiveness (9 items) and demandingness ( 7 items).(Jackson et al., 1998) Adolescents were asked to think about their mother or step-mother, or a maternal figure, in relation to each item. There were four response options, ranging from "just like my mum" to "not like my mum". Higher scores on the 9item responsiveness subscale (score range: 9-36) indicated increased responsiveness. Likewise, higher scores on the 7item demandingness subscale (score range: 7-24) indicated increased demandingness. In a late childhood sample, good internal consistency was reported for both the responsiveness (Cronbach's alpha: 0.85), and demandingness (Cronbach's alpha: 0.71) subscales.(Jackson et al., 1998)

\section{Parenting consistency}

Two five-item subscales assessing rule enforcement and discipline provided an overall measure of parenting consistency, which was derived from a previous study.(Stice et al., 1998) Rule enforcement included items such as, "I soon forgot the rules I had made", and "I changed my mind to make things easier for myself". The discipline subscale was comprised of items such as, "I usually don't find out about my child's misbehaviour", and "I seldom insisted that my child do anything". All items were scored on a five-point Likert scale, with response options ranging between strongly agree and strongly disagree. Each subscale was scored individually (score range 5-25). The scores of the rule enforcement and discipline subscales were then combined and averaged, providing an overall score of parenting consistency (score range 5-25).

\section{Parental religiosity}

Religiosity was assessed at Wave 1, asking parents how important religion was to them. Responses ranged from not important to very important. Acceptable internal consistency was previously reported for this item (Cronbach's alpha=0·68).(Mason and Windle, 2001)

\section{Family predictors}

\section{One/two parent household}

Adolescents were asked who they lived with most of the time. Response options included parents and step-parents, siblings, extended family, and non-relatives. Responses were collapsed for analyses as: two-parent household or oneparent household. Two-parent households coding was based upon the following response combinations: mother and father; mother and step-father; or father and step-mother. All adolescents in this sample reported living with at least one parent (including step-parents and guardians). Therefore, all other adolescents were coded as living in a one-parent household.

\section{Family conflict}

Three items used in a previous study assessed levels of conflict and disagreement in the family.(Ary et al., 1999) Responses options were dichotomous yes or no. Scores ranged between 3 and 6, with higher scores indicating increased levels of family conflict.

\section{Positive family relations}

Another three items measured levels of family support and relationship quality.(Ary et al., 1999) Responses were also dichotomous yes or no, and scores ranged between 3 and 6 . Higher scores indicated increased levels of positive relations in the family. 


\section{Family history of alcohol problems}

One item from the Family History-Research Diagnostic Criteria(Silins et al., 2014) was adapted to measure family history of alcohol problems. Parents were asked whether any of their "child's grandparents, aunts or uncles, on either side, ever drink heavily?".

\section{Older siblings}

Parents were asked if there were any siblings older than the child participating in the study in their household.

\section{Child predictors}

\section{Money to buy alcohol}

Children were asked whether they had money available to buy alcohol.

\section{Smoking tobacco}

Smoking tobacco use was measured using one item from the Rule-Breaking Behavior subscale from the Child Behaviour Checklist Youth Self-Report (CBCL YSR) questionnaire; "I smoke tobacco" with 3 response options "not true",

"somewhat or sometimes true" and "very true or often true".(Achenbach, 1991)

\section{Externalizing problems}

The Rule-Breaking Behavior and Aggressive Behavior subscales from the CBCL YSR were used to assess externalizing problems.(Achenbach, 1991) Good internal consistency has been reported for both the Rule-Breaking Behavior subscale (Cronbach's alpha=0·81), and the Aggressive Behavior subscale (Cronbach's alpha=0·86).(Achenbach, 1991) The 31 items from the two subscales were summed together to provide an overall externalizing score (score range: 0-62), which has excellent internal consistency (Cronbach's alpha=0·90).(Achenbach, 1991) Higher scores indicated increased levels of externalizing problems.

\section{Internalizing problems}

Internalizing problems were also assessed with the CBCL YSR, using the Withdrawn-Depressed and Anxious-Depressed subscales.(Achenbach, 1991) The Withdrawn-Depressed subscale has acceptable internal consistency (Cronbach's alpha $=0 \cdot 71$ ), while better internal consistency has been reported for the Anxious-Depressed subscale (Cronbach's alpha=0·84).(Achenbach, 1991) Higher scores on each of the subscales indicated increased levels of internalizing problems.

\section{Social problems}

The CBCL YSR was also used to assess Social Problems, a measure of peer socialising and acceptance by peers. The 11item scale has acceptable internal consistency (Cronbach's alpha=0 74).(Achenbach, 1991) Higher scores indicated increased levels of social problems.

\section{Peer predictors}

\section{Peer use of alcohol and/or tobacco}

This was adapted from the 2011 Monitoring the Future (MTF) survey.(Johnston et al., 2013) Six items asked adolescents about their peers' quantity and frequency of alcohol consumption, and smoking tobacco. Each item had five response options, ranging from none to all (of their peers). Items were summed (score range: 6-30), and higher scores indicated higher levels of peer alcohol and/or tobacco use.

\section{Peer disapproval of alcohol and/or tobacco use}

Another four items from the 2011 MTF survey(Johnston et al., 2013) were also used. Adolescents were asked how they thought their close friends would feel about them: smoking cigarettes, consuming any alcohol, consuming 1-2 drinks daily, and binge drinking over weekends. Each item had three response options: not disapprove, disapprove, and strongly disapprove. These items were summed (score range: 4-12), with a higher score indicating more peer disapproval of substance use. 


\section{MISSING DATA}

The presence of missing data raises the possibility of introducing bias into the results if data is not missing completely at random. In order to counter this when conducting the fixed effects models, missing data for covariates was imputed using multiple imputation.

Around $20 \%$ of the cohort had missing data for at least one variable in the four waves, although no individual variable had more than 5\% missing. As suggested by Mackinnon (2010), further detail on missing data is included in

Supplementary Table S1.(Mackinnon, 2010) Only cases with outcome data (drinking at Wave 4) were included, that is, outcome data was not imputed. Because imputation was not conducted for the outcome variable, only those who completed the final wave were included. That is, data was missing primarily due to failure to answer individual questions.

Imputation was conducted using chained logit, mlogit and linear regression equations to impute missing data for binary, categorical variables and continuous variables respectively. All variables included as predictors in the final model were included in the imputation. In addition, equivalent variables from other waves were also included in the imputation, even when not included in the final model (for example, 'alcohol specific rules' scores from Waves 1, 2 and 3 were included in the imputation models, while only Wave 3 was included in the final model).

Imputation was conducted using the "mi" commands of Stata 13.1. Allowing less than $1 \%$ tolerance for power falloff, 20 imputations were used.(Graham, 2007)

\section{REFERENCES}

Achenbach, T. M. (1991). Manual for the youth self-report and 1991 profile, Burlington, University of Vermont.

Ary, D. V., Duncan, T. E., Duncan, S. C. \& Hops, H. (1999). Adolescent problem behavior: The influence of parents and peers. Behaviour Research \& Therapy, 37.

Australian Institute of Health \& Welfare (2008). 2007 National Drug Strategy Household Survey: First results. Canberra: Author.

Graham, J. W., Olchowski, A. E., \& Gilreath, T. D. (2007). How many imputations are really needed? some practical clarifications of multiple imputation theory. Prevention Science, 8, 7.

Jackson, C., Henrikson, L. \& Foshee, V. A. (1998). The Authoritative Parenting Index: Predicting health risk behaviors among children and adolescents. Health Education \& Behavior, 25, 319-337.

Johnston, L. D., Bachman, J. G. \& O'malley, P. M. (2013). Monitoring the Future questionnaire responses from the nation's high school seniors, 2011. Ann Arbor, MI: Institute for Social Research, University of Michigan.

Komro, K. A., Maldonado-Molina, M. M., Tobler, A. L., Bonds, J. R. \& Muller, K. E. (2007). Effects of home access and availability of alcohol on young adolescents' alcohol use. Addiction, 102.

Mackinnon, A. (2010). The use and reporting of multiple imputation in medical research - a review. Journal of Internal Medicine, 268, 586-593.

Mason, W. A. \& Windle, M. (2001). Family, religious, school and peer influences on adolescent alcohol use: A longitudinal study. Journal of Studies on Alcohol \& Drugs, 62, 44.

Silins, E., Horwood, L. J., Patton, G. C., Fergusson, D. M., Olsson, C. A., Hutchinson, D. M., Spry, E., Toumbourou, J. W., Degenhardt, L., Swift, W., Coffey, C., Tait, R. J., Letcher, P., Copeland, J. \& Mattick, R. P. (2014). Young adult sequelae of adolescent cannabis use: an integrative analysis. The Lancet Psychiatry, 1, 286-293.

Small, S. A. \& Kerns, D. (1993). Unwanted sexual activity among peers during early and middle adolescence: Incidence and risk factors. Journal of Marriage and Family, 55.

Stice, E., Barrera Jr, M. \& Chassin, L. (1998). Prospective differential prediction of adolescent alcohol use and problem use: Examining the mechanisms of effect. Journal of Abnormal Psychology, 107, 616-628.

Van Der Vorst, H., Engels, R., Meeus, W., Dekovic, M. \& Van Leeuwe, J. (2005). The role of alcohol-specific socialization in adolescents' drinking behaviour. Addiction, 100, 1464-76. 
Table S1 The 10 most cost common patterns of missing data for multiple imputation

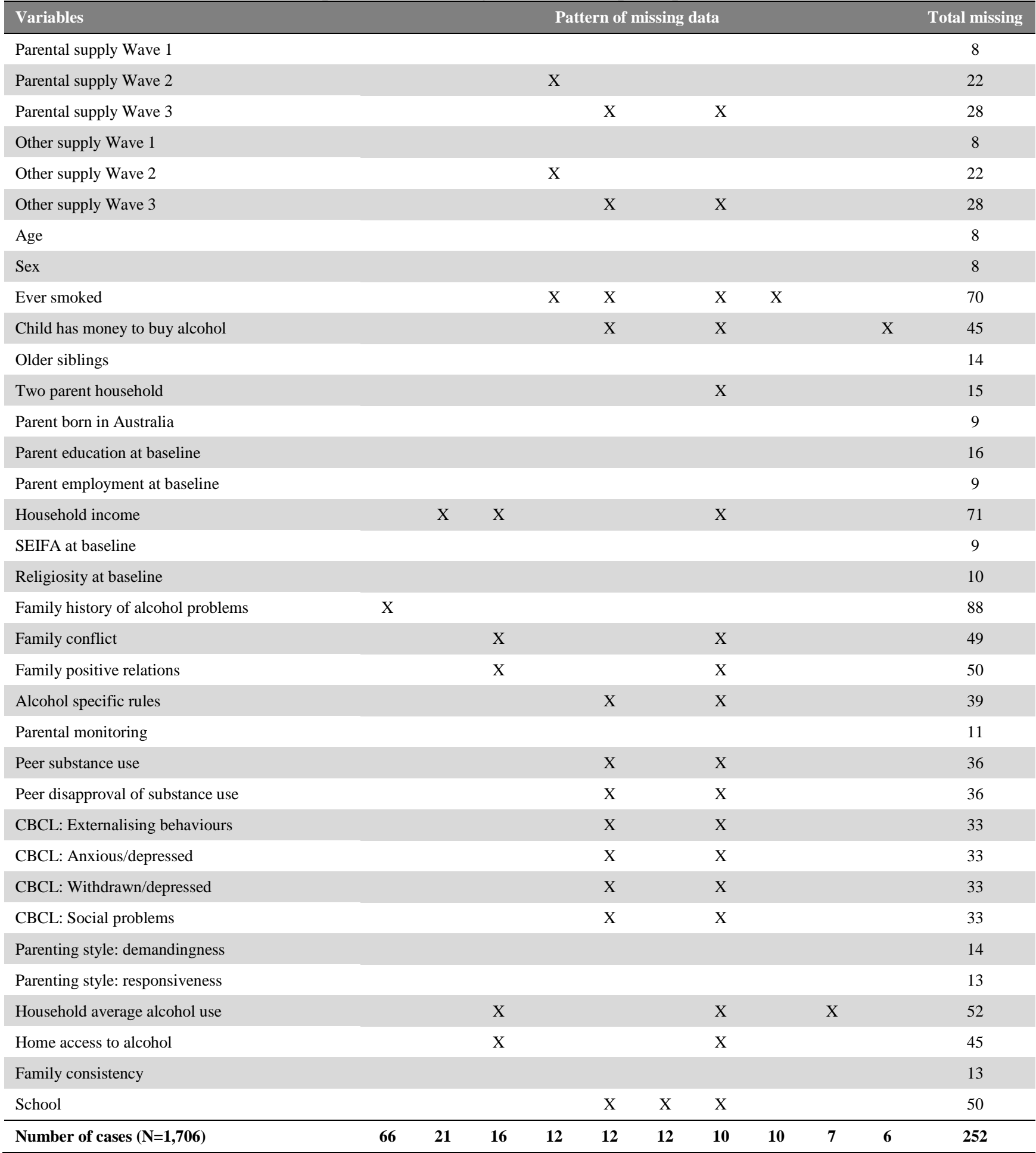

Note: Row totals indicate total number missing for variable; Column totals indicate number missing in specific pattern; $\mathrm{X}$ indicates missing data for that variable in that pattern 


\section{Supplementary Tables}

Table S2 Frequency and percent of supply by all categories of "Other Supply" for Waves 1-3

Percentage of adolescents reporting supply of alcohol from all types of other supply (n of participants at each Wave)

\begin{tabular}{|c|c|c|c|}
\hline Source of other supply & $\begin{array}{c}\text { Wave 1 } \\
(n=1911)\end{array}$ & $\begin{array}{c}\text { Wave } 2 \\
(n=1837)\end{array}$ & $\begin{array}{c}\text { Wave } 3 \\
(n=1786)\end{array}$ \\
\hline Other adult/family friend/relative & $100(5.2 \%)$ & $187(10.1 \%)$ & $242(13.3 \%)$ \\
\hline Sibling & $48(2.5 \%)$ & $79(4.3 \%)$ & $132(7.3 \%)$ \\
\hline Peer & $47(2.4 \%)$ & $139(7.5 \%)$ & $232(12.8 \%)$ \\
\hline Religious service & $80(4.2 \%)$ & $109(5.9 \%)$ & $119(6.5 \%)$ \\
\hline Self & $42(2.2 \%)$ & $98(5.3 \%)$ & $147(8.1 \%)$ \\
\hline
\end{tabular}

Frequency and percent of sample receiving alcohol from each of the Other Supply categories; other supply is combined into a single category for all analyses. Supply in each of the three waves used to predict outcomes is presented, for Wave 4 only outcome data was used. 
Table S3 Odds ratios and $95 \%$ CIs for associations of source of supply at current wave, and drinking whole drinks at the subsequent wave

\begin{tabular}{|c|c|c|c|c|c|}
\hline \multirow{2}{*}{ Variables } & & \multicolumn{2}{|c|}{ Unadjusted Odds Ratios } & \multicolumn{2}{|c|}{ Adjusted Odds Ratios } \\
\hline & & OR $(95 \% \mathrm{CI})$ & p-value & OR $(95 \% \mathrm{CI})$ & p-value \\
\hline \multirow{2}{*}{ Current wave parental supply } & No & 1.00 & $\mathrm{p}<0.001$ & 1.00 & $\mathrm{p}<0.001$ \\
\hline & Yes & $5.71(4.41,7.39)$ & & $1.80(1.33,2.45)$ & \\
\hline \multirow{2}{*}{ Current wave other supply* } & No & 1.00 & $\mathrm{p}<0.001$ & 1.00 & $\mathrm{p}<0.001$ \\
\hline & Yes & $12.73(10.01,16.19)$ & & $2.53(1.86,3.45)$ & \\
\hline \multirow{3}{*}{ Time } & Time period 1 (W1 to $\mathrm{W} 2)$ & 1.00 & $\mathrm{p}<0.001$ & 1.00 & $\mathrm{p}<0.001$ \\
\hline & Time period 2 (W2 to $\mathrm{W} 3)$ & $5.40(3.69,7.89)$ & $* * *$ & $1.45(1.05,2.01)$ & $*$ \\
\hline & Time period 3 (W3 to W4) & $43.26(26.50,70.61)$ & $* * *$ & $4.75(3.32,6.78)$ & $* * *$ \\
\hline \multicolumn{6}{|l|}{ Parental Predictors } \\
\hline \multicolumn{2}{|c|}{ Parental average alcohol use (frequency x quantity)\# } & $1.00(1.00,1.00)$ & $\mathrm{p}<0.001$ & $1.00(1.00,1.00)$ & $\mathrm{p}=0.001$ \\
\hline \multicolumn{2}{|c|}{ Home access to and availability of alcoholt } & $0.99(0.96,1.03)$ & $\mathrm{p}=0.638$ & $0.00(0.00,0.00)$ & $\mathrm{p}<0.001$ \\
\hline \multirow{2}{*}{$\begin{array}{l}\text { Parental alcohol specific } \\
\text { rules§ }\end{array}$} & Linear & $0.77(0.74,0.81)$ & $\mathrm{p}<0.001$ & & $\mathrm{p}=0.002$ \\
\hline & Polynomial & & & & $\mathrm{p}<0.001$ \\
\hline \multicolumn{2}{|l|}{ Parental monitoring } & $0.79(0.75,0.82)$ & $\mathrm{p}<0.001$ & $0.93(0.88,0.98)$ & $\mathrm{p}=0.003$ \\
\hline \multicolumn{2}{|c|}{ Authoritative parenting: demandingness $\uparrow$} & $0.85(0.81,0.88)$ & $\mathrm{p}<0.001$ & $0.99(0.95,1.03)$ & $\mathrm{p}=0.717$ \\
\hline \multicolumn{2}{|c|}{ Authoritative parenting: responsiveness $\dagger$} & $0.87(0.84,0.90)$ & $\mathrm{p}<0.001$ & $0.94(0.91,0.98)$ & $\mathrm{p}=0.001$ \\
\hline \multicolumn{2}{|l|}{ Parenting consistency } & $0.82(0.77,0.86)$ & $\mathrm{p}<0.001$ & $0.93(0.88,0.98)$ & $\mathrm{p}=0.007$ \\
\hline \multirow{2}{*}{$\begin{array}{l}\text { Parental religiosity at } \\
\text { baseline } \dagger\end{array}$} & Not important/A little important & 1.00 & $\mathrm{p}<0.001$ & 1.00 & $\mathrm{p}=0.035$ \\
\hline & Pretty important/Very important & $0.48(0.32,0.70)$ & & $0.69(0.49,0.97)$ & \\
\hline \multirow{2}{*}{ Parent born in Australia $†$ t } & No & 1.00 & $\mathrm{p}=0.304$ & & \\
\hline & Yes & $1.21(0.84,1.76)$ & & & \\
\hline \multirow{3}{*}{ Parent education at baseline $\dagger+$} & High school or less & 1.00 & $\mathrm{p}=0.830$ & & \\
\hline & Diploma, Trade, non-trade & $1.06(0.72,1.55)$ & & & \\
\hline & University degree & $0.94(0.63,1.40)$ & & & \\
\hline \multirow{3}{*}{$\begin{array}{l}\text { Parent employment at } \\
\text { baseline } \dagger+\end{array}$} & Employed (full-time/part-time) & 1.00 & $\mathrm{p}=0.462$ & & \\
\hline & Unemployed (in workforce) & $0.93(0.58,1.47)$ & & & \\
\hline & Unemployed (not in workforce) & $1.43(0.78,2.60)$ & & & \\
\hline \multicolumn{6}{|l|}{ Familial Predictors } \\
\hline \multirow{2}{*}{ Two parent household } & No & 1.00 & $\mathrm{p}<0.001$ & 1.00 & $\mathrm{p}=0.021$ \\
\hline & Yes & $3.00(2.20,4.09)$ & & $1.48(1.06,2.06)$ & \\
\hline \multicolumn{2}{|l|}{ Family conflict } & $1.23(1.08,1.40)$ & $\mathrm{p}=0.002$ & $0.93(0.81,1.07)$ & $\mathrm{p}=0.322$ \\
\hline \multicolumn{2}{|l|}{ Family positive relations } & $0.68(0.55,0.83)$ & $\mathrm{p}<0.001$ & $1.04(0.82,1.33)$ & $\mathrm{p}=0.736$ \\
\hline Relative socioeconomic & Low & 1.00 & $\mathrm{p}=0.014$ & 1.00 & $\mathrm{p}=0.206$ \\
\hline disadvantage of area of & Medium & $0.44(0.26,0.77)$ & $* *$ & $0.71(0.45,1.13)$ & \\
\hline & High & $0.57(0.33,0.96)$ & $*$ & $0.68(0.44,1.05)$ & \\
\hline & Up to $\$ 34,000$ & 1.00 & $\mathrm{p}=0.006$ & 1.00 & $\mathrm{p}=0.633$ \\
\hline Ho & $\$ 35,000$ to $\$ 80,000$ & $0.60(0.37,0.98)$ & $*$ & $0.89(0.53,1.49)$ & \\
\hline Household income & $\$ 81,000$ to $\$ 180,000$ & $0.44(0.27,0.73)$ & $* *$ & $0.85(0.50,1.46)$ & \\
\hline & $\$ 181,001$ or more & $0.64(0.36,1.15)$ & & $1.08(0.58,1.99)$ & \\
\hline Family history of alcohol & No & 1.00 & $\mathrm{p}=0.176$ & & \\
\hline problems $† \ddagger$ & Yes & $1.24(0.91,1.70)$ & & & \\
\hline Old noriblin & No & 1.00 & $\mathrm{p}=0.215$ & & \\
\hline Older siblings $T$ t & Yes & $1.21(0.89,1.64)$ & & & \\
\hline Child Predictors & & & & & \\
\hline Child has money to buy & No & 1.00 & $\mathrm{p}<0.001$ & 1.00 & $\mathrm{p}=0.122$ \\
\hline alcohol & Yes & $2.72(2.10,3.52)$ & & $1.23(0.95,1.61)$ & \\
\hline Smoling & No & 1.00 & $\mathrm{p}<0.001$ & 1.00 & $\mathrm{p}=0.019$ \\
\hline smoking & Yes & $28.36(13.93,57.75)$ & & $2.69(1.18,6.12)$ & \\
\hline
\end{tabular}




\begin{tabular}{lllll}
\hline Child Behavior Checklist: Externalising & $1.08(1.07,1.09)$ & $\mathrm{p}<0.001$ & $1.03(1.01,1.05)$ & $\mathrm{p}<0.001$ \\
\hline Child Behavior Checklist: Anxious/depressed & $1.03(1.02,1.05)$ & $\mathrm{p}<0.001$ & $1.02(0.99,1.05)$ & $\mathrm{p}=0.207$ \\
\hline Child Behavior Checklist: Withdrawn/depressed & $1.05(1.03,1.07)$ & $\mathrm{p}<0.001$ & $0.97(0.94,1.00)$ & $\mathrm{p}=0.077$ \\
\hline Child Behavior Checklist: Social problems & $1.03(1.01,1.05)$ & $\mathrm{p}=0.002$ & $0.94(0.91,0.97)$ & $\mathrm{p}=0.001$ \\
\hline Age $\quad$ Male & $3.32(2.42,4.56)$ & $\mathrm{p}<0.001$ & $2.17(1.62,2.90)$ & $\mathrm{p}<0.001$ \\
\hline \multirow{2}{*}{ Fex $\quad 1.00$} & $\mathrm{p}<0.001$ & 1.00 & $\mathrm{p}<0.001$ \\
& $1.97(1.39,2.78)$ & & $1.80(1.31,2.45)$ & \\
\hline Peer Predictors & & & & \\
\hline Peer use of alcohol and/or tobacco & $1.48(1.43,1.53)$ & $\mathrm{p}<0.001$ & $1.22(1.17,1.27)$ & $\mathrm{p}<0.001$ \\
\hline Peer disapproval of alcohol and/or tobacco use & $0.63(0.59,0.66)$ & $\mathrm{p}<0.001$ & $0.88(0.82,0.93)$ & $\mathrm{p}<0.001$ \\
\hline
\end{tabular}

Results of random intercept mixed-effects logistic regression models. Data included as paired waves, with covariates from one wave and outcome from subsequent wave. A significant random effect was observed for the multivariate logistic mixed model of drinking whole drinks (School intercept SD: 0.39; ID intercept SD: 1.51; p<0.001). * Included supply from: family friend or relative or adult; brother/sister; friends; received as part of religious service; got it themselves. $\uparrow$ Variable does not vary over time: baseline value was used + Unadjusted analyses were not significant so variable was not included in adjusted model. $\S$ Because of nonlinearity, fractional polynomials were included in the adjusted model- In order to avoid misinterpretation, only p-values are shown in the table, not odds ratios. Notably, from a clinical perspective, each one-point increase on the externalising measure and social problems causes an incremental increase in odds of drinking and bingeing. \# The OR for parental average alcohol use is $>1$, however due to rounding, the upper and lower values are both 1.00 (also in tables S3-S8). 
Table S4 Odds ratios and $95 \%$ CIs for associations of source of supply at current wave, and binge drinking at the subsequent wave

\begin{tabular}{|c|c|c|c|c|c|}
\hline \multirow{2}{*}{ Variables } & & \multicolumn{2}{|c|}{ Unadjusted Odds Ratios } & \multicolumn{2}{|c|}{ Adjusted Odds Ratios } \\
\hline & & OR $(95 \% \mathrm{CI})$ & p-value & OR $(95 \% \mathrm{CI})$ & p-value \\
\hline \multirow{2}{*}{ Current wave parental supply } & No & 1.00 & $\mathrm{p}<0.001$ & 1.00 & $\mathrm{p}=0.518$ \\
\hline & Yes & $4.66(3.48,6.24)$ & & $1.12(0.80,1.55)$ & \\
\hline \multirow{2}{*}{ Current wave other supply* } & No & 1.00 & $\mathrm{p}<0.001$ & 1.00 & $\mathrm{p}<0.001$ \\
\hline & Yes & $15.39(11.66,20.32)$ & & $3.51(2.53,4.87)$ & \\
\hline \multirow{3}{*}{ Time } & Time period 1 (W1 to $\mathrm{W} 2)$ & 1.00 & $\mathrm{p}<0.001$ & 1.00 & $\mathrm{p}<0.001$ \\
\hline & Time period 2 (W2 to W3) & $3.32(2.22,4.95)$ & $* * *$ & $1.15(0.79,1.67)$ & \\
\hline & Time period 3 (W3 to $\mathrm{W} 4)$ & $18.94(11.83,30.30)$ & $* * *$ & $3.13(2.13,4.60)$ & $* * *$ \\
\hline \multicolumn{6}{|l|}{ Parental Predictors } \\
\hline \multicolumn{2}{|c|}{ Parental average alcohol use (frequency x quantity)\# } & $1.00(1.00,1.00)$ & $\mathrm{p}<0.001$ & $1.00(1.00,1.00)$ & $\mathrm{p}=0.077$ \\
\hline \multicolumn{2}{|c|}{ Home access to and availability of alcoholț } & $0.97(0.93,1.01)$ & $\mathrm{p}=0.112$ & & \\
\hline \multirow{2}{*}{$\begin{array}{l}\text { Parental alcohol specific } \\
\text { rules§ }\end{array}$} & Linear & $0.76(0.73,0.80)$ & $\mathrm{p}<0.001$ & & $\mathrm{p}=0.008$ \\
\hline & Polynomial & & & & $\mathrm{p}<0.001$ \\
\hline \multicolumn{2}{|l|}{ Parental monitoring } & $0.76(0.72,0.80)$ & $\mathrm{p}<0.001$ & $0.91(0.86,0.95)$ & $\mathrm{p}<0.001$ \\
\hline \multicolumn{2}{|c|}{ Authoritative parenting: demandingness $\dagger$} & $0.84(0.80,0.88)$ & $\mathrm{p}<0.001$ & $1.00(0.96,1.05)$ & $\mathrm{p}=0.967$ \\
\hline \multicolumn{2}{|c|}{ Authoritative parenting: responsiveness $\dagger$} & $0.87(0.84,0.91)$ & $\mathrm{p}<0.001$ & $0.97(0.94,1.01)$ & $\mathrm{p}=0.171$ \\
\hline \multicolumn{2}{|l|}{ Parenting consistency } & $0.82(0.77,0.87)$ & $\mathrm{p}<0.001$ & $0.95(0.89,1.00)$ & $\mathrm{p}=0.064$ \\
\hline \multirow{2}{*}{$\begin{array}{l}\text { Parental religiosity at } \\
\text { baseline } \dagger\end{array}$} & Not important/A little important & 1.00 & $\mathrm{p}=0.001$ & 1.00 & $\mathrm{p}=0.051$ \\
\hline & Pretty important/Very important & $0.47(0.30,0.74)$ & & $0.69(0.47,1.00)$ & \\
\hline \multirow{2}{*}{ Parent born in Australia $† t$} & No & 1.00 & $\mathrm{p}=0.964$ & & \\
\hline & Yes & $1.01(0.66,1.55)$ & & & \\
\hline \multirow{3}{*}{ Parent education at baseline $\uparrow t$} & High school or less & 1.00 & $\mathrm{p}=0.316$ & & \\
\hline & Diploma, Trade, non-trade & $1.13(0.73,1.75)$ & & & \\
\hline & University degree & $0.80(0.51,1.28)$ & & & \\
\hline \multirow{3}{*}{$\begin{array}{l}\text { Parent employment at } \\
\text { baselinett }\end{array}$} & Employed (full-time/part-time) & 1.00 & $\mathrm{p}=0.926$ & & \\
\hline & Unemployed (in workforce) & $0.98(0.57,1.67)$ & & & \\
\hline & Unemployed (not in workforce) & $0.86(0.42,1.80)$ & & & \\
\hline \multicolumn{6}{|l|}{ Familial Predictors } \\
\hline \multirow{2}{*}{ Two parent household } & Yes & 1.00 & $\mathrm{p}<0.001$ & 1.00 & $\mathrm{p}=0.049$ \\
\hline & No & $3.10(2.17,4.42)$ & & $1.43(1.00,2.05)$ & \\
\hline \multicolumn{2}{|l|}{ Family conflict } & $1.29(1.11,1.49)$ & $\mathrm{p}=0.001$ & $0.97(0.83,1.14)$ & $\mathrm{p}=0.731$ \\
\hline \multicolumn{2}{|l|}{ Family positive relations } & $0.67(0.53,0.84)$ & $\mathrm{p}=0.001$ & $0.97(0.76,1.25)$ & $\mathrm{p}=0.831$ \\
\hline Relative socioeconomic & Low & 1.00 & $\mathrm{p}=0.043$ & 1.00 & $\mathrm{p}=0.986$ \\
\hline disadvantage of area of & Medium & $0.46(0.24,0.86)$ & $*$ & $1.01(0.62,1.65)$ & \\
\hline & High & $0.54(0.30,0.97)$ & $*$ & $0.96(0.61,1.52)$ & \\
\hline & Up to $\$ 34,000$ & 1.00 & $\mathrm{p}<0.001$ & 1.00 & $\mathrm{p}=0.098$ \\
\hline Houshold income & $\$ 35,000$ to $\$ 80,000$ & $0.53(0.30,0.92)$ & $*$ & $0.88(0.51,1.52)$ & \\
\hline nousenora mine & $\$ 81,000$ to $\$ 180,000$ & $0.34(0.19,0.60)$ & $* * *$ & $0.83(0.47,1.47)$ & \\
\hline & $\$ 181,001$ or more & $0.62(0.32,1.19)$ & & $1.34(0.71,2.55)$ & \\
\hline Family history of alcohol & No & 1.00 & $\mathrm{p}=0.421$ & & \\
\hline problems $\dagger+$ & Yes & $1.16(0.81,1.65)$ & & & \\
\hline Older ciblino & No & 1.00 & $\mathrm{p}=0.284$ & & \\
\hline Older siblings $\uparrow !$ & Yes & $1.21(0.85,1.72)$ & & & \\
\hline Child Predictors & & & & & \\
\hline Child has money to buy & No & 1.00 & $\mathrm{p}<0.001$ & 1.00 & $\mathrm{p}=0.730$ \\
\hline alcohol & Yes & $2.60(1.93,3.51)$ & & $1.05(0.78,1.42)$ & \\
\hline Smoking & No & 1.00 & $\mathrm{p}<0.001$ & 1.00 & $\mathrm{p}=0.129$ \\
\hline smoking & Yes & $22.85(11.87,44.00)$ & & $1.71(0.86,3.42)$ & \\
\hline
\end{tabular}




\begin{tabular}{lllll}
\hline Child Behavior Checklist: Externalising & $1.09(1.07,1.10)$ & $\mathrm{p}<0.001$ & $1.03(1.02,1.05)$ & $\mathrm{p}<0.001$ \\
\hline Child Behavior Checklist: Anxious/depressed & $1.02(1.01,1.04)$ & $\mathrm{p}=0.011$ & $0.99(0.96,1.02)$ & $\mathrm{p}=0.343$ \\
\hline Child Behavior Checklist: Withdrawn/depressed & $1.05(1.03,1.07)$ & $\mathrm{p}<0.001$ & $0.99(0.96,1.03)$ & $\mathrm{p}=0.628$ \\
\hline Child Behavior Checklist: Social problems & $1.03(1.01,1.05)$ & $\mathrm{p}=0.004$ & $0.96(0.93,0.99)$ & $\mathrm{p}=0.022$ \\
\hline Age $\quad$ Male & $3.34(2.33,4.78)$ & $\mathrm{p}<0.001$ & $1.88(1.39,2.55)$ & $\mathrm{p}<0.001$ \\
\hline \multirow{2}{*}{ Fex $\quad 1.00$} & $\mathrm{p}=0.005$ & 1.00 & $\mathrm{p}=0.010$ \\
& $1.75(1.18,2.59)$ & & $1.55(1.11,2.16)$ & \\
\hline Peer Predictors & & & & \\
\hline Peer use of alcohol and/or tobacco & $1.41(1.36,1.45)$ & $\mathrm{p}<0.001$ & $1.17(1.12,1.21)$ & $\mathrm{p}<0.001$ \\
\hline Peer disapproval of alcohol and/or tobacco use & $0.60(0.57,0.64)$ & $\mathrm{p}<0.001$ & $0.86(0.80,0.92)$ & $\mathrm{p}<0.001$ \\
\hline
\end{tabular}

Results of random intercept mixed-effects logistic regression models. Data included as paired waves, with covariates from one wave and outcome from subsequent wave. A significant random effect was observed for the multivariate logistic mixed model of binge drinking (School intercept SD: 0.29; ID intercept SD: 1.33; p<0·001). ${ }^{*}$ Included supply from: family friend or relative or adult; brother/sister; friends; received as part of religious service; got it themselves. Variable does not vary over time: baseline value was used. ${ }^{*}$ Unadjusted analyses were not significant so variable was not included in adjusted model. ${ }^{\S}$ Because of nonlinearity, fractional polynomials were included in the adjusted model. In order to avoid misinterpretation, only p-values are shown in the table, not odds ratios. Notably, from a clinical perspective, each one-point increase on the externalising measure and social problems causes an incremental increase in odds of drinking and bingeing. 
Table S5 Dose response relationship - Odds ratios and 95\% CIs for associations of number of waves of supply and other covariates, and drinking whole drinks and binge drinking

\begin{tabular}{|c|c|c|c|c|c|}
\hline \multirow{2}{*}{ Variables } & & \multicolumn{2}{|c|}{$\begin{array}{c}\text { Adjusted Odds of } \\
\text { Drinking Whole Drinks }\end{array}$} & \multicolumn{2}{|c|}{$\begin{array}{l}\text { Adjusted Odds of } \\
\text { Binge Drinking }\end{array}$} \\
\hline & & $\begin{array}{l}\text { OR } \\
(95 \% \mathrm{CI})\end{array}$ & p-value & $\begin{array}{l}\text { OR } \\
(95 \% \mathrm{CI})\end{array}$ & p-value \\
\hline \multirow{4}{*}{$\begin{array}{l}\text { Number of waves of } \\
\text { parental supply* }\end{array}$} & 0 & 1.00 & $\mathrm{p}=0.003$ & 1.00 & $\mathrm{p}=0.102$ \\
\hline & 1 & $1.48(1.03,2.12)$ & $*$ & $1.20(0.80,1.81)$ & \\
\hline & 2 & $1.92(1.29,2.85)$ & $* *$ & $1.41(0.91,2.18)$ & \\
\hline & 3 & $2.15(1.21,3.82)$ & $* *$ & $2.05(1.13,3.72)$ & * \\
\hline \multirow{4}{*}{$\begin{array}{l}\text { Number of waves of } \\
\text { other supply* }\end{array}$} & 0 & 1.00 & $\mathrm{p}<0.001$ & 1.00 & $\mathrm{p}<0.001$ \\
\hline & 1 & $2.57(1.84,3.61)$ & $* * *$ & $3.08(2.09,4.53)$ & $* * *$ \\
\hline & 2 & $3.87(2.45,6.09)$ & $* * *$ & $3.24(2.01,5.21)$ & $* * *$ \\
\hline & 3 & $2.26(1.09,4.70)$ & $*$ & $2.57(1.24,5.32)$ & * \\
\hline \multicolumn{6}{|l|}{ Parental Predictors } \\
\hline \multicolumn{2}{|c|}{ Parental average alcohol use } & $1.00(1.00,1.00)$ & $\mathrm{p}<0.001$ & $1.00(1.00,1.00)$ & $\mathrm{p}=0.011$ \\
\hline \multicolumn{2}{|c|}{ Home access to and availability of alcohol $\leftarrow$} & $0.58(0.42,0.81)$ & $\mathrm{p}=0.001$ & $0.60(0.41,0.87)$ & $\mathrm{p}=0.008$ \\
\hline \multicolumn{2}{|c|}{ Parental alcohol specific rulesł } & $0.99(0.95,1.03)$ & $\mathrm{p}=0.626$ & $0.95(0.91,0.99)$ & $\mathrm{p}=0.015$ \\
\hline \multicolumn{2}{|l|}{ Parental monitoring $\ddagger$} & $0.97(0.92,1.02)$ & $\mathrm{p}=0.228$ & $0.92(0.87,0.97)$ & $\mathrm{p}=0.001$ \\
\hline \multicolumn{2}{|c|}{ Authoritative parenting: demandingness $\uparrow$} & $1.00(0.96,1.04)$ & $\mathrm{p}=0.865$ & $0.99(0.95,1.04)$ & $\mathrm{p}=0.724$ \\
\hline \multicolumn{2}{|c|}{ Authoritative parenting: responsiveness $\dagger$} & $0.97(0.94,1.01)$ & $\mathrm{p}=0.114$ & $1.02(0.98,1.07)$ & $\mathrm{p}=0.235$ \\
\hline \multicolumn{2}{|l|}{ Parenting consistency } & $0.94(0.89,1.00)$ & $\mathrm{p}=0.040$ & $0.94(0.89,1.00)$ & $\mathrm{p}=0.064$ \\
\hline \multirow{2}{*}{$\begin{array}{l}\text { Parental religiosity at } \\
\text { baseline } \dagger\end{array}$} & Not important/A little important & 1.00 & $\mathrm{p}<0.001$ & 1.00 & $\mathrm{p}<0.001$ \\
\hline & Pretty important/Very important & $0.00(0.00,0.00)$ & & $0.00(0.00,0.00)$ & \\
\hline \multicolumn{6}{|l|}{ Familial Predictors } \\
\hline \multirow{2}{*}{ Two parent household $\dagger$} & No & 1.00 & $\mathrm{p}=0.098$ & 1.00 & $\mathrm{p}=0.944$ \\
\hline & Yes & $1.34(0.95,1.89)$ & & $0.99(0.67,1.45)$ & \\
\hline \multicolumn{2}{|l|}{ Family conflict } & $1.01(0.87,1.18)$ & $\mathrm{p}=0.869$ & $1.09(0.93,1.29)$ & $\mathrm{p}=0.291$ \\
\hline \multicolumn{2}{|l|}{ Family positive relations } & $0.94(0.73,1.19)$ & $\mathrm{p}=0.591$ & $0.94(0.72,1.21)$ & $\mathrm{p}=0.616$ \\
\hline \multirow{3}{*}{$\begin{array}{l}\text { Relative socioeconomic } \\
\text { disadvantage of area of } \\
\text { residence } \dagger\end{array}$} & Low & 1.00 & $\mathrm{p}=0.137$ & 1.00 & $\mathrm{p}=0.621$ \\
\hline & Medium & $0.65(0.42,1.01)$ & & $1.27(0.78,2.07)$ & \\
\hline & High & $0.72(0.48,1.06)$ & & $1.13(0.73,1.76)$ & \\
\hline \multirow{4}{*}{ Household income $\ddagger$} & Up to $\$ 34,000$ & 1.00 & $\mathrm{p}=0.263$ & 1.00 & $\mathrm{p}=0.273$ \\
\hline & $\$ 35,000$ to $\$ 80,000$ & $1.18(0.66,2.09)$ & & $0.90(0.49,1.64)$ & \\
\hline & $\$ 81,000$ to $\$ 180,000$ & $1.45(0.82,2.58)$ & & $0.85(0.46,1.55)$ & \\
\hline & $\$ 181,001$ or more & $1.73(0.92,3.25)$ & & $1.26(0.65,2.47)$ & \\
\hline \multicolumn{6}{|l|}{ Child Predictors } \\
\hline \multirow{2}{*}{$\begin{array}{l}\text { Child has money to buy } \\
\text { alcoholt }\end{array}$} & No & 1.00 & $\mathrm{p}=0.099$ & 1.00 & $\mathrm{p}=0.763$ \\
\hline & Yes & $1.28(0.95,1.73)$ & & $0.95(0.68,1.33)$ & \\
\hline \multirow{2}{*}{ Ever smoked* } & No & 1.00 & $\mathrm{p}=0.001$ & 1.00 & $\mathrm{p}=0.001$ \\
\hline & Yes & $3.35(1.66,6.74)$ & & $2.93(1.57,5.45)$ & \\
\hline Child Behavior Checklis & xternalising $t$ & $1.03(1.01,1.05)$ & $\mathrm{p}=0.003$ & $1.02(1.00,1.04)$ & $\mathrm{p}=0.014$ \\
\hline Child Behavior Checklis & Inxious/depressed $\$$ & $1.02(0.99,1.05)$ & $\mathrm{p}=0.308$ & $1.00(0.96,1.03)$ & $\mathrm{p}=0.795$ \\
\hline Child Behavior Checklis & Vithdrawn/depressed $\ddagger$ & $0.97(0.94,1.01)$ & $\mathrm{p}=0.108$ & $0.99(0.95,1.02)$ & $\mathrm{p}=0.468$ \\
\hline Child Behavior Checklis & ocial problems & $0.95(0.91,0.98)$ & $\mathrm{p}=0.003$ & $0.96(0.92,1.00)$ & $\mathrm{p}=0.045$ \\
\hline Age† & & $1.89(1.41,2.53)$ & $\mathrm{p}<0.001$ & $1.78(1.30,2.44)$ & $\mathrm{p}<0.001$ \\
\hline $\operatorname{Sex} \leftarrow$ & Male & 1.00 & $\mathrm{p}=0.030$ & 1.00 & $\mathrm{p}=0.487$ \\
\hline$\Delta \mathbf{N}_{1}$ & Female & $1.37(1.03,1.82)$ & & $1.12(0.81,1.54)$ & \\
\hline Peer Predictors & & & & & \\
\hline Peer substance use & & $1.14(1.10,1.19)$ & $\mathrm{p}<0.001$ & $1.11(1.06,1.16)$ & $\mathrm{p}<0.001$ \\
\hline Peer disapproval of subs & ce uset & $0.90(0.84,0.96)$ & $\mathrm{p}=0.002$ & $0.90(0.83,0.97)$ & $\mathrm{p}=0.006$ \\
\hline
\end{tabular}

* Cross-wave predictor (constructed of responses from waves $1-3 \cdot \dagger$ Baseline covariate + Wave 3 covariate 
Table S6 Incidence-rate ratios and 95\% CIs for associations of source of supply at current wave, and number of drinks consumed in the subsequent year

\begin{tabular}{|c|c|c|c|c|c|}
\hline \multirow[t]{2}{*}{ Variables } & & \multicolumn{2}{|c|}{$\begin{array}{l}\text { Unadjusted Incidence-rate } \\
\text { Ratios }\end{array}$} & \multicolumn{2}{|c|}{$\begin{array}{c}\text { Adjusted Incidence-rate } \\
\text { Ratios }\end{array}$} \\
\hline & & IRR $(95 \% \mathrm{CI})$ & p-value & IRR $(95 \%$ CI $)$ & p-value \\
\hline \multirow{2}{*}{ Current wave parental supply } & No & 1.00 & $\mathrm{p}<0.001$ & 1.00 & $\mathrm{p}<0.001$ \\
\hline & Yes & $22.58(13.26,38.45)$ & & $3.68(2.30,5.90)$ & \\
\hline \multirow{2}{*}{ Current wave other supply* } & No & 1.00 & $\mathrm{p}<0.001$ & 1.00 & $\mathrm{p}<0.001$ \\
\hline & Yes & $67.19(40.06,112.68)$ & & $2.67(1.63,4.35)$ & \\
\hline \multirow{3}{*}{ Time } & Time period 1 (W1 to W2) & 1.00 & $\mathrm{p}<0.001$ & 1.00 & $\mathrm{p}<0.001$ \\
\hline & Time period 2 (W2 to W3) & $9.55(6.19,14.73)$ & $* * *$ & $2.35(1.47,3.74)$ & $* * *$ \\
\hline & Time period 3 (W3 to W4) & $\begin{array}{l}97.45(60.93, \\
155.86)\end{array}$ & $* * *$ & $\begin{array}{l}10.70(6.52 \\
17.56)\end{array}$ & $* * *$ \\
\hline \multicolumn{6}{|l|}{ Parental Predictors } \\
\hline \multicolumn{2}{|c|}{ Parental average alcohol use (frequency $\mathrm{x}$ quantity)\# } & $1.00(1.00,1.00)$ & $\mathrm{p}<0.001$ & $1.00(1.00,1.00)$ & $\mathrm{p}=0.054$ \\
\hline \multicolumn{2}{|c|}{ Home access to and availability of alcohol } & $1.01(0.94,1.08)$ & $\mathrm{p}=0.877$ & & \\
\hline \multirow{2}{*}{$\begin{array}{l}\text { Parental alcohol specific } \\
\text { rules§ }\end{array}$} & Linear & $0.65(0.58,0.72)$ & $\mathrm{p}<0.001$ & & $\mathrm{p}=0.077$ \\
\hline & Polynomial & & & & $\mathrm{p}=0.080$ \\
\hline \multicolumn{2}{|l|}{ Parental monitoring } & $0.61(0.56,0.67)$ & $\mathrm{p}<0.001$ & $0.86(0.79,0.94)$ & $\mathrm{p}=0.001$ \\
\hline \multicolumn{2}{|c|}{ Authoritative parenting: demandingness $\dagger$} & $0.72(0.66,0.78)$ & $\mathrm{p}<0.001$ & $0.97(0.91,1.04)$ & $\mathrm{p}=0.426$ \\
\hline \multicolumn{2}{|c|}{ Authoritative parenting: responsiveness $\dagger$} & $0.77(0.72,0.82)$ & $\mathrm{p}<0.001$ & $0.90(0.85,0.96)$ & $\mathrm{p}=0.001$ \\
\hline \multicolumn{2}{|l|}{ Parenting consistency } & $0.65(0.58,0.73)$ & $\mathrm{p}<0.001$ & $0.87(0.80,0.95)$ & $\mathrm{p}=0.003$ \\
\hline \multirow{2}{*}{$\begin{array}{l}\text { Parental religiosity at } \\
\text { baseline } \dagger\end{array}$} & Not important/A little important & 1.00 & $\mathrm{p}<0.001$ & 1.00 & $\mathrm{p}=0.002$ \\
\hline & Pretty important/Very important & $0.15(0.07,0.33)$ & & $0.41(0.23,0.73)$ & \\
\hline \multirow{2}{*}{ Parent born in Australia†t } & No & 1.00 & $\mathrm{p}=0.494$ & & \\
\hline & Yes & $1.30(0.61,2.78)$ & & & \\
\hline \multirow{3}{*}{ Parent education at baseline $\dagger+$} & High school or less & 1.00 & $\mathrm{p}=0.922$ & & \\
\hline & Diploma, Trade, non-trade & $1.04(0.47,2.30)$ & & & \\
\hline & University degree & $0.89(0.39,2.03)$ & & & \\
\hline \multirow{3}{*}{$\begin{array}{l}\text { Parent employment at } \\
\text { baselinet: }\end{array}$} & Employed (full-time/part-time) & 1.00 & $\mathrm{p}=0.545$ & & \\
\hline & Unemployed (in workforce) & $0.77(0.30,1.99)$ & & & \\
\hline & Unemployed (not in workforce) & $1.77(0.51,6.19)$ & & & \\
\hline \multicolumn{6}{|l|}{ Familial Predictors } \\
\hline \multirow{2}{*}{ Two parent household } & Yes & 1.00 & $\mathrm{p}<0.001$ & 1.00 & $\mathrm{p}=0.001$ \\
\hline & No & $8.20(4.50,14.95)$ & & $2.41(1.45,4.00)$ & \\
\hline \multicolumn{2}{|l|}{ Family conflict } & $1.46(1.13,1.89)$ & $\mathrm{p}=0.004$ & $0.95(0.76,1.20)$ & $\mathrm{p}=0.693$ \\
\hline \multicolumn{2}{|l|}{ Family positive relations } & $0.52(0.35,0.78)$ & $\mathrm{p}=0.002$ & $1.19(0.81,1.73)$ & $\mathrm{p}=0.375$ \\
\hline & Low & 1.00 & $\mathrm{p}=0.014$ & 1.00 & $\mathrm{p}=0.921$ \\
\hline disadvantage of area of & Medium & $0.19(0.06,0.58)$ & $* *$ & $0.61(0.28,1.34)$ & \\
\hline & High & $0.38(0.13,1.12)$ & & $0.58(0.29,1.18)$ & \\
\hline & Up to $\$ 34,000$ & 1.00 & $\mathrm{p}=0.059$ & & \\
\hline Household income & $\$ 35,000$ to $\$ 80,000$ & $0.51(0.19,1.37)$ & & & \\
\hline & $\$ 81,000$ to $\$ 180,000$ & $0.35(0.13,0.98)$ & $*$ & & \\
\hline & $\$ 181,001$ or more & $0.80(0.25,2.63)$ & & & \\
\hline Family history of alcohol & No & 1.00 & $\mathrm{p}=0.250$ & & \\
\hline problems $\dagger \ddagger$ & Yes & $1.30(0.83,2.02)$ & & & \\
\hline Oldor ciblinget & No & 1.00 & $\mathrm{p}=0.408$ & & \\
\hline Older siblings $\uparrow ?$ & Yes & $1.30(0.70,2.43)$ & & & \\
\hline Child Predictors & & & & & \\
\hline Child has money to buy & No & 1.00 & $\mathrm{p}<0.001$ & 1.00 & $\mathrm{p}=0.241$ \\
\hline alcohol & Yes & $4.94(3.07,7.94)$ & & $1.28(0.85,1.94)$ & \\
\hline Smoking & No & 1.00 & $\mathrm{p}<0.001$ & 1.00 & $\mathrm{p}=0.197$ \\
\hline
\end{tabular}




\begin{tabular}{|c|c|c|c|c|}
\hline Yes & $27.39(8.60,87.22)$ & & $0.54(0.21,1.38)$ & \\
\hline Child Behavior Checklist: Externalising & $1.16(1.14,1.19)$ & $\mathrm{p}<0.001$ & $1.06(1.03,1.09)$ & $\mathrm{p}<0.001$ \\
\hline Child Behavior Checklist: Anxious/depressed & $1.05(1.02,1.08)$ & $\mathrm{p}=0.001$ & $1.03(0.99,1.07)$ & $\mathrm{p}=0.169$ \\
\hline Child Behavior Checklist: Withdrawn/depressed & $1.10(1.06,1.14)$ & $\mathrm{p}<0.001$ & $0.96(0.91,1.01)$ & $\mathrm{p}=0.090$ \\
\hline Child Behavior Checklist: Social problems & $1.05(1.01,1.09)$ & $\mathrm{p}=0.014$ & $0.91(0.86,0.95)$ & $\mathrm{p}<0.001$ \\
\hline Age & $12.51(6.57,23.80)$ & $\mathrm{p}<0.001$ & $4.81(2.97,7.78)$ & $\mathrm{p}<0.001$ \\
\hline \multirow{2}{*}{$\begin{array}{l}\text { Male } \\
\text { Female }\end{array}$} & 1.00 & $\mathrm{p}=0.001$ & 1.00 & $\mathrm{p}<0.001$ \\
\hline & $3.16(1.57,6.37)$ & & $2.54(1.52,4.26)$ & \\
\hline \multicolumn{5}{|l|}{ Peer Predictors } \\
\hline Peer use of alcohol and/or tobacco & $1.96(1.85,2.09)$ & $\mathrm{p}<0.001$ & $1.37(1.29,1.46)$ & $\mathrm{p}<0.001$ \\
\hline Peer disapproval of alcohol and/or tobacco use & $0.39(0.35,0.43)$ & $\mathrm{p}<0.001$ & $0.76(0.68,0.84)$ & $\mathrm{p}<0.001$ \\
\hline
\end{tabular}

Results of random intercept mixed-effects logistic regression models. Data included as paired waves, with covariates from one wave and outcome from subsequent wave. A significant random effect was observed for the multivariate logistic mixed model of drinking whole drinks (School intercept SD: 0.69; ID intercept SD: 3·11; p<0 001). * Included supply from: family friend or relative or adult; brother/sister; friends; received as part of religious service; got it themselves. $\uparrow$ Variable does not vary over time: baseline value was used + Unadjusted analyses were not significant so variable was not included in adjusted model. § Because of nonlinearity, fractional polynomials were included in the adjusted model- In order to avoid misinterpretation, only p-values are shown in the table, not odds ratios. Notably, from a clinical perspective, each one-point increase on the externalising measure and social problems causes an incremental increase in odds of drinking and bingeing. \# The IRR for parental average alcohol use is $>1$, however due to rounding, the upper and lower values are both 1.00 (also in tables S3-S8). 
Table S7 Incident rate ratios and $95 \%$ CIs for associations of source of supply at current wave, and number of drinks consumed on typical occasion drinking at the subsequent wave

\begin{tabular}{|c|c|c|c|}
\hline \multirow[t]{2}{*}{ Variables } & & \multicolumn{2}{|c|}{$\begin{array}{c}\text { Adjusted Rate of } \\
\text { Typical Quantity of } \\
\text { Drinks }\end{array}$} \\
\hline & & IRR $(95 \%$ CI) & p-value \\
\hline \multirow{2}{*}{ Current wave parental supply } & No & 1.00 & $\mathrm{p}=0.028$ \\
\hline & Yes & $0.89(0.79,0.99)$ & \\
\hline \multirow{2}{*}{ Current wave other supply* } & No & 1.00 & $\mathrm{p}<0.001$ \\
\hline & Yes & $1.25(1.12,1.40)$ & \\
\hline \multirow{3}{*}{ Time } & Time period 1 (W1 to $\mathrm{W} 2)$ & 1.00 & $\mathrm{p}<0.001$ \\
\hline & Time period 2 (W2 to $\mathrm{W} 3$ ) & $1.31(1.13,1.52)$ & $* * *$ \\
\hline & Time period 3 (W3 to $\mathrm{W} 4)$ & $1.11(0.96,1.29)$ & \\
\hline \multicolumn{4}{|l|}{ Parental Predictors } \\
\hline \multicolumn{2}{|c|}{ Parental average alcohol use (frequency x quantity)\# } & $1.00(1.00,1.00)$ & $\mathrm{p}=0.719$ \\
\hline \multicolumn{4}{|c|}{ Home access to and availability of alcohol } \\
\hline \multirow{2}{*}{$\begin{array}{l}\text { Parental alcohol specific } \\
\text { rules§ }\end{array}$} & Linear & & $\mathrm{p}=0.997$ \\
\hline & Polynomial & & $\mathrm{p}=0.703$ \\
\hline \multicolumn{2}{|l|}{ Parental monitoring } & $0.99(0.98,1.01)$ & $\mathrm{p}=0.438$ \\
\hline \multicolumn{2}{|c|}{ Authoritative parenting: demandingness $\dagger$} & $1.00(0.98,1.01)$ & $\mathrm{p}=0.883$ \\
\hline \multicolumn{2}{|c|}{ Authoritative parenting: responsiveness $\dagger$} & $1.00(0.99,1.01)$ & $\mathrm{p}=0.866$ \\
\hline \multicolumn{2}{|l|}{ Parenting consistency } & $0.99(0.98,1.01)$ & $\mathrm{p}=0.608$ \\
\hline \multirow{2}{*}{$\begin{array}{l}\text { Parental religiosity at } \\
\text { baseline } \dagger\end{array}$} & Not important/A little important & 1.00 & $\mathrm{p}=0.003$ \\
\hline & Pretty important/Very important & $0.81(0.71,0.93)$ & \\
\hline \multirow{2}{*}{ Parent born in Australia $\uparrow t$} & No & & \\
\hline & Yes & & \\
\hline \multirow{3}{*}{ Parent education at baseline $\uparrow t$} & High school or less & & \\
\hline & Diploma, Trade, non-trade & & \\
\hline & University degree & & \\
\hline \multirow{3}{*}{$\begin{array}{l}\text { Parent employment at } \\
\text { baseline } \dagger+\end{array}$} & Employed (full-time/part-time) & & \\
\hline & Unemployed (in workforce) & & \\
\hline & Unemployed (not in workforce) & & \\
\hline \multicolumn{4}{|l|}{ Familial Predictors } \\
\hline \multirow{2}{*}{ Two parent household } & Yes & 1.00 & $\mathrm{p}<0.001$ \\
\hline & No & $0.00(0.00,0.00)$ & \\
\hline \multicolumn{2}{|l|}{ Family conflict } & $1.01(0.93,1.10)$ & $\mathrm{p}=0.762$ \\
\hline \multicolumn{2}{|l|}{ Family positive relations } & $0.99(0.88,1.12)$ & $\mathrm{p}=0.871$ \\
\hline \multirow{3}{*}{$\begin{array}{l}\text { Relative socioeconomic } \\
\text { disadvantage of area of } \\
\text { residencet }\end{array}$} & Low & 1.00 & $\mathrm{p}=0.241$ \\
\hline & Medium & $1.07(0.91,1.26)$ & \\
\hline & High & $1.14(0.98,1.32)$ & \\
\hline \multirow{4}{*}{ Household income } & Up to $\$ 34,000$ & 1.00 & $\mathrm{p}=0.841$ \\
\hline & $\$ 35,000$ to $\$ 80,000$ & $1.08(0.91,1.29)$ & \\
\hline & $\$ 81,000$ to $\$ 180,000$ & $1.08(0.89,1.31)$ & \\
\hline & $\$ 181,001$ or more & $1.09(0.87,1.36)$ & \\
\hline Family history of alcohol & No & & \\
\hline problems $\dagger+$ & Yes & & \\
\hline Older ciblingst+ & No & & \\
\hline Oider siomings t+ & Yes & & \\
\hline Child Predictors & & & \\
\hline Child has money to buy & No & 1.00 & $\mathrm{p}=0.518$ \\
\hline alcohol & Yes & $0.96(0.87,1.08)$ & \\
\hline Smoking & No & 1.00 & $\mathrm{p}=0.091$ \\
\hline
\end{tabular}




\begin{tabular}{|c|c|c|}
\hline Yes & $1.15(0.98,1.35)$ & \\
\hline Child Behavior Checklist: Externalising & $1.01(1.00,1.01)$ & $\mathrm{p}=0.003$ \\
\hline Child Behavior Checklist: Anxious/depressed & $1.00(0.99,1.01)$ & $\mathrm{p}=0.929$ \\
\hline Child Behavior Checklist: Withdrawn/depressed & $1.00(0.99,1.02)$ & $\mathrm{p}=0.418$ \\
\hline Child Behavior Checklist: Social problems & $0.99(0.98,1.00)$ & $\mathrm{p}=0.044$ \\
\hline Age & $1.09(0.99,1.20)$ & $\mathrm{p}=0.079$ \\
\hline Male & 1.00 & $\mathrm{p}=0.626$ \\
\hline Female & $0.97(0.87,1.09)$ & \\
\hline
\end{tabular}

Peer Predictors

Peer use of alcohol and/or tobacco $\quad 1.01(1.00,1.02) \quad \mathrm{p}=0.132$

Peer disapproval of alcohol and/or tobacco use $\quad 0.98(0.96,1.01) \quad \mathrm{p}=0.137$

Results of random intercept mixed-effects negative binomial regression model- Data included as paired waves, with covariates from one wave and outcome from subsequent wave. A significant random effect was observed (School intercept SD: 0.00; ID intercept SD: 0.32; p<0.001). * Included supply from: family friend or relative or adult; brother/sister; friends; received as part of religious service; got it themselves $\uparrow \uparrow$ Variable does not vary over time. 
Table S8 Dose response relationship - Odds ratios and 95\% CIs for associations of number of waves of supply and other covariates, and drinking whole drinks and binge drinking (non-imputed sensitivity analysis)

\begin{tabular}{|c|c|c|c|c|c|}
\hline \multirow{2}{*}{ Variables } & & \multicolumn{2}{|c|}{$\begin{array}{c}\text { Adjusted Odds of } \\
\text { Drinking Whole Drinks }\end{array}$} & \multicolumn{2}{|c|}{$\begin{array}{l}\text { Adjusted Odds of } \\
\text { Binge Drinking }\end{array}$} \\
\hline & & $\begin{array}{l}\text { OR } \\
(95 \% \mathrm{CI})\end{array}$ & p-value & $\begin{array}{l}\text { OR } \\
(95 \% \mathrm{CI})\end{array}$ & p-value \\
\hline \multirow{4}{*}{$\begin{array}{l}\text { Number of waves of } \\
\text { parental supply* }\end{array}$} & 0 & 1.00 & $\mathrm{p}=0.002$ & 1.00 & $\mathrm{p}=0.100$ \\
\hline & 1 & $1.50(1.03,2.18)$ & $*$ & $1.28(0.83,1.97)$ & \\
\hline & 2 & $2.06(1.37,3.09)$ & $* * *$ & $1.50(0.96,2.37)$ & \\
\hline & 3 & $2.22(1.22,4.04)$ & $* *$ & $2.06(1.10,3.86)$ & $*$ \\
\hline \multirow{4}{*}{$\begin{array}{l}\text { Number of waves of } \\
\text { other supply* }\end{array}$} & 0 & 1.00 & $\mathrm{p}<0.001$ & 1.00 & $\mathrm{p}<0.001$ \\
\hline & 1 & $2.66(1.87,3.79)$ & $* * *$ & $3.10(2.07,4.65)$ & $* * *$ \\
\hline & 2 & $3.88(2.40,6.28)$ & $* * *$ & $3.35(2.03,5.54)$ & $* * *$ \\
\hline & 3 & $2.32(1.08,4.99)$ & $*$ & $2.79(1.29,6.02)$ & $* *$ \\
\hline \multicolumn{6}{|l|}{ Parental Predictors } \\
\hline \multicolumn{2}{|c|}{ Parental average alcohol use } & $1.00(1.00,1.00)$ & $\mathrm{p}<0.001$ & $1.00(1.00,1.00)$ & $\mathrm{p}=0.004$ \\
\hline \multicolumn{2}{|c|}{ Home access to and availability of alcohol } & $0.55(0.39,0.79)$ & $\mathrm{p}=0.001$ & $0.58(0.39,0.87)$ & $\mathrm{p}=0.008$ \\
\hline \multicolumn{2}{|c|}{ Parental alcohol specific rulesł } & $1.00(0.95,1.04)$ & $\mathrm{p}=0.932$ & $0.96(0.92,1.00)$ & $\mathrm{p}=0.036$ \\
\hline \multicolumn{2}{|l|}{ Parental monitoring $\ddagger$} & $0.96(0.92,1.02)$ & $\mathrm{p}=0.174$ & $0.93(0.88,0.98)$ & $\mathrm{p}=0.005$ \\
\hline \multicolumn{2}{|c|}{ Authoritative parenting: demandingness $\dagger$} & $1.01(0.96,1.05)$ & $\mathrm{p}=0.753$ & $1.01(0.96,1.06)$ & $\mathrm{p}=0.653$ \\
\hline \multicolumn{2}{|c|}{ Authoritative parenting: responsiveness $\dagger$} & $0.97(0.94,1.01)$ & $\mathrm{p}=0.123$ & $1.01(0.97,1.06)$ & $\mathrm{p}=0.480$ \\
\hline \multicolumn{2}{|l|}{ Parenting consistency } & $0.94(0.89,1.00)$ & $\mathrm{p}=0.033$ & $0.93(0.87,0.99)$ & $\mathrm{p}=0.029$ \\
\hline \multirow{2}{*}{$\begin{array}{l}\text { Parental religiosity at } \\
\text { baseline } \dagger\end{array}$} & Not important/A little important & 1.00 & $\mathrm{p}<0.001$ & 1.00 & $\mathrm{p}<0.001$ \\
\hline & Pretty important/Very important & $0.00(0.00,0.00)$ & & $0.00(0.00,0.00)$ & \\
\hline \multicolumn{6}{|l|}{ Familial Predictors } \\
\hline \multirow{2}{*}{ Two parent household $\dagger$} & No & 1.00 & $\mathrm{p}=0.140$ & 1.00 & $\mathrm{p}=0.986$ \\
\hline & Yes & $1.32(0.91,1.92)$ & & $1.00(0.66,1.51)$ & \\
\hline \multicolumn{2}{|l|}{ Family conflict $\$$} & $1.01(0.86,1.18)$ & $\mathrm{p}=0.932$ & $1.08(0.90,1.28)$ & $\mathrm{p}=0.411$ \\
\hline \multicolumn{2}{|l|}{ Family positive relations: } & $0.96(0.74,1.23)$ & $\mathrm{p}=0.740$ & $0.89(0.68,1.17)$ & $\mathrm{p}=0.408$ \\
\hline \multirow{3}{*}{$\begin{array}{l}\text { Relative socioeconomic } \\
\text { disadvantage of area of } \\
\text { residence } \dagger\end{array}$} & Low & 1.00 & $\mathrm{p}=0.063$ & 1.00 & $\mathrm{p}=0.731$ \\
\hline & Medium & $0.59(0.37,0.94)$ & $*$ & $1.22(0.73,2.06)$ & \\
\hline & High & $0.66(0.44,0.99)$ & $*$ & $1.07(0.67,1.71)$ & \\
\hline \multirow{4}{*}{ Household income $\ddagger$} & Up to $\$ 34,000$ & 1.00 & $\mathrm{p}=0.435$ & 1.00 & $\mathrm{p}=0.267$ \\
\hline & $\$ 35,000$ to $\$ 80,000$ & $1.08(0.58,1.99)$ & & $0.87(0.46,1.65)$ & \\
\hline & $\$ 81,000$ to $\$ 180,000$ & $1.25(0.68,2.32)$ & & $0.81(0.42,1.56)$ & \\
\hline & $\$ 181,001$ or more & $1.55(0.78,3.04)$ & & $1.23(0.60,2.53)$ & \\
\hline \multicolumn{6}{|l|}{ Child Predictors } \\
\hline \multirow{2}{*}{$\begin{array}{l}\text { Child has money to buy } \\
\text { alcohol } \ddagger\end{array}$} & No & 1.00 & $\mathrm{p}=0.081$ & 1.00 & $\mathrm{p}=0.386$ \\
\hline & Yes & $1.32(0.97,1.81)$ & & $0.86(0.60,1.22)$ & \\
\hline \multirow{2}{*}{ Ever smoked* } & No & 1.00 & $\mathrm{p}=0.001$ & 1.00 & $\mathrm{p}<0.001$ \\
\hline & Yes & $3.28(1.60,6.74)$ & & $3.17(1.68,5.99)$ & \\
\hline Child Behavior Checklis & xternalising & $1.03(1.01,1.05)$ & $\mathrm{p}=0.002$ & $1.03(1.01,1.05)$ & $\mathrm{p}=0.013$ \\
\hline Child Behavior Checklis & Inxious/depressed & $1.02(0.98,1.05)$ & $\mathrm{p}=0.322$ & $0.99(0.95,1.03)$ & $\mathrm{p}=0.595$ \\
\hline Child Behavior Checklis & Vithdrawn/depressed $\ddagger$ & $0.98(0.94,1.01)$ & $\mathrm{p}=0.205$ & $0.99(0.95,1.03)$ & $\mathrm{p}=0.740$ \\
\hline Child Behavior Checklis & ocial problems & $0.94(0.90,0.97)$ & $\mathrm{p}=0.001$ & $0.95(0.91,0.99)$ & $\mathrm{p}=0.025$ \\
\hline Age $\dagger$ & & $1.99(1.46,2.70)$ & $\mathrm{p}<0.001$ & $1.88(1.35,2.63)$ & $\mathrm{p}<0.001$ \\
\hline Sext & Male & 1.00 & $\mathrm{p}=0.015$ & 1.00 & $\mathrm{p}=0.448$ \\
\hline $\operatorname{sex} 1$ & Female & $1.45(1.07,1.97)$ & & $1.14(0.81,1.60)$ & \\
\hline Peer Predictors & & & & & \\
\hline Peer substance use $\downarrow$ & & $1.14(1.10,1.19)$ & $\mathrm{p}<0.001$ & $1.12(1.07,1.18)$ & $\mathrm{p}<0.001$ \\
\hline Peer disapproval of subs & ce uset & $0.90(0.84,0.97)$ & $\mathrm{p}=0.006$ & $0.92(0.85,1.00)$ & $\mathrm{p}=0.040$ \\
\hline
\end{tabular}

$*$ Cross-wave predictor (constructed of responses from waves $1-3 \cdot \dagger$ Baseline covariate $\$$ Wave 3 covariate 
Table S9 Dose response relationship - Odds ratios and 95\% CIs for associations of number of waves of supply and other covariates, and drinking whole drinks and binge drinking (sensitivity analysis - missing outcomes coded no)

\begin{tabular}{|c|c|c|c|c|c|}
\hline \multirow{2}{*}{ Variables } & & \multicolumn{2}{|c|}{$\begin{array}{c}\text { Adjusted Odds of } \\
\text { Drinking Whole Drinks }\end{array}$} & \multicolumn{2}{|c|}{$\begin{array}{l}\text { Adjusted Odds of } \\
\text { Binge Drinking }\end{array}$} \\
\hline & & $\begin{array}{l}\text { OR } \\
(95 \% \mathrm{CI})\end{array}$ & p-value & $\begin{array}{l}\text { OR } \\
(95 \% \mathrm{CI})\end{array}$ & p-value \\
\hline \multirow{4}{*}{$\begin{array}{l}\text { Number of waves of } \\
\text { parental supply* }\end{array}$} & 0 & 1.00 & $\mathrm{p}=0.007$ & 1.00 & $\mathrm{p}=0.127$ \\
\hline & 1 & $1.39(1.00,1.94)$ & & $1.19(0.81,1.75)$ & \\
\hline & 2 & $1.78(1.23,2.57)$ & $* *$ & $1.42(0.93,2.15)$ & \\
\hline & 3 & $1.88(1.13,3.12)$ & $*$ & $1.85(1.08,3.17)$ & $*$ \\
\hline \multirow{4}{*}{$\begin{array}{l}\text { Number of waves of } \\
\text { other supply* }\end{array}$} & 0 & 1.00 & $\mathrm{p}<0.001$ & 1.00 & $\mathrm{p}<0.001$ \\
\hline & 1 & $2.50(1.82,3.43)$ & $* * *$ & $3.02(2.09,4.35)$ & $* * *$ \\
\hline & 2 & $3.42(2.25,5.19)$ & $* * *$ & $3.25(2.05,5.13)$ & $* * *$ \\
\hline & 3 & $1.62(0.87,3.02)$ & & $1.96(1.01,3.79)$ & $*$ \\
\hline \multicolumn{6}{|l|}{ Parental Predictors } \\
\hline \multicolumn{2}{|c|}{ Parental average alcohol use } & $1.00(1.00,1.00)$ & $\mathrm{p}<0.001$ & $1.00(1.00,1.00)$ & $\mathrm{p}=0.012$ \\
\hline \multicolumn{2}{|c|}{ Home access to and availability of alcoholt } & $0.64(0.47,0.86)$ & $\mathrm{p}=0.003$ & $0.66(0.46,0.94)$ & $\mathrm{p}=0.020$ \\
\hline \multicolumn{2}{|c|}{ Parental alcohol specific rulest } & $1.00(0.97,1.04)$ & $\mathrm{p}=0.993$ & $0.97(0.93,1.00)$ & $\mathrm{p}=0.046$ \\
\hline \multicolumn{2}{|l|}{ Parental monitoring $\ddagger$} & $0.99(0.94,1.03)$ & $\mathrm{p}=0.571$ & $0.94(0.90,0.99)$ & $\mathrm{p}=0.020$ \\
\hline \multicolumn{2}{|c|}{ Authoritative parenting: demandingness $\uparrow$} & $0.98(0.94,1.02)$ & $\mathrm{p}=0.292$ & $0.98(0.94,1.02)$ & $\mathrm{p}=0.330$ \\
\hline \multicolumn{2}{|c|}{ Authoritative parenting: responsiveness $\dagger$} & $0.98(0.95,1.02)$ & $\mathrm{p}=0.339$ & $1.03(0.99,1.06)$ & $\mathrm{p}=0.152$ \\
\hline \multicolumn{2}{|l|}{ Parenting consistencył } & $0.96(0.91,1.00)$ & $\mathrm{p}=0.072$ & $0.95(0.90,1.01)$ & $\mathrm{p}=0.078$ \\
\hline \multirow{2}{*}{$\begin{array}{l}\text { Parental religiosity at } \\
\text { baseline } \dagger\end{array}$} & Not important/A little important & 1.00 & $\mathrm{p}<0.001$ & 1.00 & $\mathrm{p}<0.001$ \\
\hline & Pretty important/Very important & $0.00(0.00,0.00)$ & & $0.00(0.00,0.00)$ & \\
\hline \multicolumn{6}{|l|}{ Familial Predictors } \\
\hline \multirow{2}{*}{ Two parent household $\dagger$} & No & 1.00 & $\mathrm{p}=0.974$ & 1.00 & $\mathrm{p}=0.255$ \\
\hline & Yes & $1.01(0.74,1.37)$ & & $0.81(0.57,1.16)$ & \\
\hline \multicolumn{2}{|l|}{ Family conflict } & $1.01(0.88,1.16)$ & $\mathrm{p}=0.863$ & $1.06(0.91,1.24)$ & $\mathrm{p}=0.442$ \\
\hline \multicolumn{2}{|l|}{ Family positive relations: } & $0.94(0.75,1.17)$ & $\mathrm{p}=0.585$ & $0.92(0.72,1.17)$ & $\mathrm{p}=0.495$ \\
\hline \multirow{3}{*}{$\begin{array}{l}\text { Relative socioeconomic } \\
\text { disadvantage of area of } \\
\text { residence } \dagger\end{array}$} & Low & 1.00 & $\mathrm{p}=0.142$ & 1.00 & $\mathrm{p}=0.763$ \\
\hline & Medium & $0.67(0.45,1.00)$ & & $1.18(0.75,1.87)$ & \\
\hline & High & $0.77(0.54,1.10)$ & & $1.13(0.74,1.71)$ & \\
\hline \multirow{4}{*}{ Household income } & Up to $\$ 34,000$ & 1.00 & $\mathrm{p}=0.582$ & 1.00 & $\mathrm{p}=0.361$ \\
\hline & $\$ 35,000$ to $\$ 80,000$ & $0.99(0.59,1.66)$ & & $0.81(0.46,1.42)$ & \\
\hline & $\$ 81,000$ to $\$ 180,000$ & $1.18(0.70,1.98)$ & & $0.76(0.43,1.35)$ & \\
\hline & $\$ 181,001$ or more & $1.31(0.74,2.32)$ & & $1.05(0.56,1.99)$ & \\
\hline \multicolumn{6}{|l|}{ Child Predictors } \\
\hline \multirow{2}{*}{$\begin{array}{l}\text { Child has money to buy } \\
\text { alcoholt }\end{array}$} & No & 1.00 & $\mathrm{p}=0.110$ & 1.00 & $\mathrm{p}=0.850$ \\
\hline & Yes & $1.26(0.95,1.68)$ & & $0.97(0.70,1.34)$ & \\
\hline \multirow{2}{*}{ Ever smoked* } & No & 1.00 & $\mathrm{p}=0.368$ & 1.00 & $\mathrm{p}=0.103$ \\
\hline & Yes & $1.28(0.75,2.16)$ & & $1.55(0.91,2.62)$ & \\
\hline Child Behavior Checklis & xternalising & $1.02(1.01,1.04)$ & $\mathrm{p}=0.009$ & $1.02(1.00,1.04)$ & $\mathrm{p}=0.018$ \\
\hline Child Behavior Checklis & Anxious/depressed $\$$ & $1.01(0.98,1.04)$ & $\mathrm{p}=0.412$ & $1.00(0.96,1.03)$ & $\mathrm{p}=0.861$ \\
\hline Child Behavior Checklis & Vithdrawn/depressed $\ddagger$ & $0.97(0.94,1.01)$ & $\mathrm{p}=0.111$ & $0.99(0.95,1.02)$ & $\mathrm{p}=0.447$ \\
\hline Child Behavior Checklis & ocial problems & $0.96(0.93,1.00)$ & $\mathrm{p}=0.028$ & $0.97(0.93,1.01)$ & $\mathrm{p}=0.109$ \\
\hline Age† & & $1.66(1.29,2.13)$ & $\mathrm{p}<0.001$ & $1.62(1.23,2.14)$ & $\mathrm{p}=0.001$ \\
\hline $\mathrm{Sex}^{\dagger}$ & Male & 1.00 & $\mathrm{p}=0.018$ & 1.00 & $\mathrm{p}=0.338$ \\
\hline $\operatorname{sex}_{1}$ & Female & $1.37(1.06,1.78)$ & & $1.16(0.86,1.57)$ & \\
\hline Peer Predictors & & & & & \\
\hline Peer substance use $\ddagger$ & & $1.10(1.06,1.14)$ & $\mathrm{p}<0.001$ & $1.09(1.04,1.13)$ & $\mathrm{p}<0.001$ \\
\hline Peer disapproval of subs & ce uset & $0.92(0.86,0.98)$ & $\mathrm{p}=0.009$ & $0.91(0.85,0.99)$ & $\mathrm{p}=0.019$ \\
\hline
\end{tabular}

$*$ Cross-wave predictor (constructed of responses from waves $1-3 \cdot \dagger$ Baseline covariate $\$$ Wave 3 covariate 
Table S10 Dose response relationship - Odds ratios and 95\% CIs for associations of number of waves of supply and other covariates, and drinking whole drinks and binge drinking (sensitivity analysis-missing outcomes coded yes)

\begin{tabular}{|c|c|c|c|c|c|}
\hline \multirow[t]{2}{*}{ Variables } & & \multicolumn{2}{|c|}{$\begin{array}{c}\text { Adjusted Odds of } \\
\text { Drinking Whole Drinks }\end{array}$} & \multicolumn{2}{|c|}{$\begin{array}{l}\text { Adjusted Odds of } \\
\text { Binge Drinking }\end{array}$} \\
\hline & & $\begin{array}{l}\text { OR } \\
(95 \% \mathrm{CI})\end{array}$ & p-value & $\begin{array}{l}\text { OR } \\
(95 \% \mathrm{CI})\end{array}$ & p-value \\
\hline \multirow{4}{*}{$\begin{array}{l}\text { Number of waves of } \\
\text { parental supply* }\end{array}$} & 0 & 1.00 & $\mathrm{p}=0.002$ & 1.00 & $\mathrm{p}=0.108$ \\
\hline & 1 & $1.46(1.07,2.01)$ & $*$ & $1.27(0.90,1.78)$ & \\
\hline & 2 & $1.80(1.28,2.55)$ & $* *$ & $1.41(0.99,2.01)$ & \\
\hline & 3 & $1.80(1.08,3.02)$ & $*$ & $1.68(1.02,2.77)$ & * \\
\hline \multirow{4}{*}{$\begin{array}{l}\text { Number of waves of } \\
\text { other supply* }\end{array}$} & 0 & 1.00 & $\mathrm{p}<0.001$ & 1.00 & $\mathrm{p}<0.001$ \\
\hline & 1 & $1.90(1.41,2.57)$ & $* * *$ & $1.84(1.34,2.54)$ & $* * *$ \\
\hline & 2 & $2.82(1.85,4.31)$ & $* * *$ & $1.98(1.32,2.99)$ & $* *$ \\
\hline & 3 & $1.86(0.95,3.64)$ & & $1.79(0.96,3.35)$ & \\
\hline \multicolumn{6}{|l|}{ Parental Predictors } \\
\hline \multicolumn{2}{|c|}{ Parental average alcohol use $\$$} & $1.00(1.00,1.00)$ & $\mathrm{p}=0.003$ & $1.00(1.00,1.00)$ & $\mathrm{p}=0.121$ \\
\hline \multicolumn{2}{|c|}{ Home access to and availability of alcohol $\$$} & $0.77(0.59,1.00)$ & $\mathrm{p}=0.046$ & $0.85(0.65,1.12)$ & $\mathrm{p}=0.246$ \\
\hline \multicolumn{2}{|c|}{ Parental alcohol specific rules } & $0.98(0.94,1.02)$ & $\mathrm{p}=0.342$ & $0.95(0.92,0.99)$ & $\mathrm{p}=0.011$ \\
\hline \multicolumn{2}{|l|}{ Parental monitoring $\ddagger$} & $0.99(0.94,1.03)$ & $\mathrm{p}=0.520$ & $0.95(0.91,0.99)$ & $\mathrm{p}=0.026$ \\
\hline \multicolumn{2}{|c|}{ Authoritative parenting: demandingness $\dagger$} & $1.00(0.97,1.04)$ & $\mathrm{p}=0.983$ & $1.00(0.97,1.04)$ & $\mathrm{p}=0.907$ \\
\hline \multicolumn{2}{|c|}{ Authoritative parenting: responsiveness $\dagger$} & $0.97(0.94,1.00)$ & $\mathrm{p}=0.062$ & $1.00(0.97,1.04)$ & $\mathrm{p}=0.797$ \\
\hline \multicolumn{2}{|l|}{ Parenting consistency } & $0.96(0.92,1.00)$ & $\mathrm{p}=0.061$ & $0.96(0.92,1.01)$ & $\mathrm{p}=0.088$ \\
\hline \multirow{2}{*}{$\begin{array}{l}\text { Parental religiosity at } \\
\text { baseline† } \dagger\end{array}$} & Not important/A little important & 1.00 & $\mathrm{p}<0.001$ & 1.00 & $\mathrm{p}<0.001$ \\
\hline & Pretty important/Very important & $0.00(0.00,0.00)$ & & $0.00(0.00,0.00)$ & \\
\hline \multicolumn{6}{|l|}{ Familial Predictors } \\
\hline \multirow{2}{*}{ Two parent household $\dagger$} & No & 1.00 & $\mathrm{p}<0.001$ & 1.00 & $\mathrm{p}=0.005$ \\
\hline & Yes & $1.74(1.30,2.32)$ & & $1.53(1.13,2.06)$ & \\
\hline \multicolumn{2}{|l|}{ Family conflict $\ddagger$} & $1.08(0.94,1.23)$ & $\mathrm{p}=0.288$ & $1.11(0.96,1.27)$ & $\mathrm{p}=0.148$ \\
\hline \multicolumn{2}{|l|}{ Family positive relations } & $0.97(0.78,1.21)$ & $\mathrm{p}=0.796$ & $0.97(0.77,1.21)$ & $\mathrm{p}=0.754$ \\
\hline \multirow{3}{*}{$\begin{array}{l}\text { Relative socioeconomic } \\
\text { disadvantage of area of } \\
\text { residence† }\end{array}$} & Low & 1.00 & $\mathrm{p}=0.174$ & 1.00 & $\mathrm{p}=0.343$ \\
\hline & Medium & $0.76(0.53,1.11)$ & & $1.22(0.84,1.79)$ & \\
\hline & High & $0.72(0.51,1.02)$ & & $0.98(0.69,1.41)$ & \\
\hline \multirow{4}{*}{ Household income } & Up to $\$ 34,000$ & 1.00 & $\mathrm{p}=0.419$ & 1.00 & $\mathrm{p}=0.366$ \\
\hline & $\$ 35,000$ to $\$ 80,000$ & $1.09(0.66,1.82)$ & & $0.94(0.58,1.54)$ & \\
\hline & $\$ 81,000$ to $\$ 180,000$ & $1.25(0.75,2.08)$ & & $0.91(0.56,1.48)$ & \\
\hline & $\$ 181,001$ or more & $1.48(0.83,2.65)$ & & $1.23(0.71,2.14)$ & \\
\hline \multicolumn{6}{|l|}{ Child Predictors } \\
\hline \multirow{2}{*}{$\begin{array}{l}\text { Child has money to buy } \\
\text { alcoholł }\end{array}$} & No & 1.00 & $\mathrm{p}=0.353$ & 1.00 & $\mathrm{p}=0.593$ \\
\hline & Yes & $1.13(0.87,1.48)$ & & $0.92(0.69,1.23)$ & \\
\hline \multirow{2}{*}{ Ever smoked* } & No & 1.00 & $\mathrm{p}=0.001$ & 1.00 & $\mathrm{p}<0.001$ \\
\hline & Yes & $3.19(1.61,6.33)$ & & $2.78(1.61,4.83)$ & \\
\hline Child Behavior Checklis & Xxternalisingt & $1.02(1.00,1.04)$ & $\mathrm{p}=0.016$ & $1.02(1.00,1.03)$ & $\mathrm{p}=0.040$ \\
\hline Child Behavior Checklis & Inxious/depressed $\$$ & $1.01(0.98,1.04)$ & $\mathrm{p}=0.496$ & $1.00(0.97,1.03)$ & $\mathrm{p}=0.916$ \\
\hline Child Behavior Checklis & Vithdrawn/depressed $\ddagger$ & $0.99(0.96,1.02)$ & $\mathrm{p}=0.351$ & $1.00(0.96,1.03)$ & $\mathrm{p}=0.794$ \\
\hline Child Behavior Checklis & ocial problems & $0.96(0.93,0.99)$ & $\mathrm{p}=0.013$ & $0.97(0.94,1.00)$ & $\mathrm{p}=0.076$ \\
\hline Age $\dagger$ & & $1.50(1.18,1.91)$ & $\mathrm{p}=0.001$ & $1.38(1.09,1.76)$ & $\mathrm{p}=0.008$ \\
\hline Sext & Male & 1.00 & $\mathrm{p}=0.236$ & 1.00 & $\mathrm{p}=0.781$ \\
\hline $\operatorname{Sex} \uparrow$ & Female & $1.16(0.91,1.48)$ & & $0.96(0.75,1.24)$ & \\
\hline Peer Predictors & & & & & \\
\hline Peer substance use $\ddagger$ & & $1.11(1.07,1.16)$ & $\mathrm{p}<0.001$ & $1.08(1.04,1.12)$ & $\mathrm{p}<0.001$ \\
\hline Peer disapproval of subs & ce uset & $0.91(0.86,0.97)$ & $\mathrm{p}=0.003$ & $0.93(0.87,0.99)$ & $\mathrm{p}=0.017$ \\
\hline
\end{tabular}

* Cross-wave predictor (constructed of responses from waves $1-3 \cdot \dagger$ Baseline covariate $\$$ Wave 3 covariate. 
Table S11 Adolescent rearing environment for Waves 1-3

Parents in rearing environment n $(\%)$

\begin{tabular}{lccc} 
& Wave 1 & Wave 2 & Wave 3 \\
\hline Both mother and father & $1534(80.4 \%)$ & $1445(78.9 \%)$ & $1359(76.8 \%)$ \\
Mother only & $311(16.3 \%)$ & $316(17.3 \%)$ & $318(18.0 \%)$ \\
$\begin{array}{l}\text { Father only } \\
\begin{array}{l}\text { No parents in rearing } \\
\text { environment }\end{array}\end{array}$ & $37(1.9 \%)$ & $46(2.5 \%)$ & $71(4.0 \%)$ \\
\hline
\end{tabular}

Table S12 Presence of adults other than parents in the household for Waves 1-3

Other adults in rearing environment

$$
\text { n }(\%)
$$

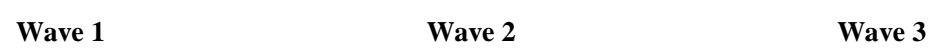

\begin{tabular}{lccc} 
& Wave 1 & Wave 2 & Wave 3 \\
\hline No other adults in household & $1839(96.4 \%)$ & $1766(96.5 \%)$ & $1720(97.2 \%)$ \\
Other adults in household & $69(3.6 \%)$ & $65(3.5 \%)$ & $49(2.8 \%)$ \\
\hline
\end{tabular}




\section{Supplementary Figures}

\section{Figure S1 Interaction of parental supply and externalising z-score}

(a) Drinking whole drinks $(p=0.007)$

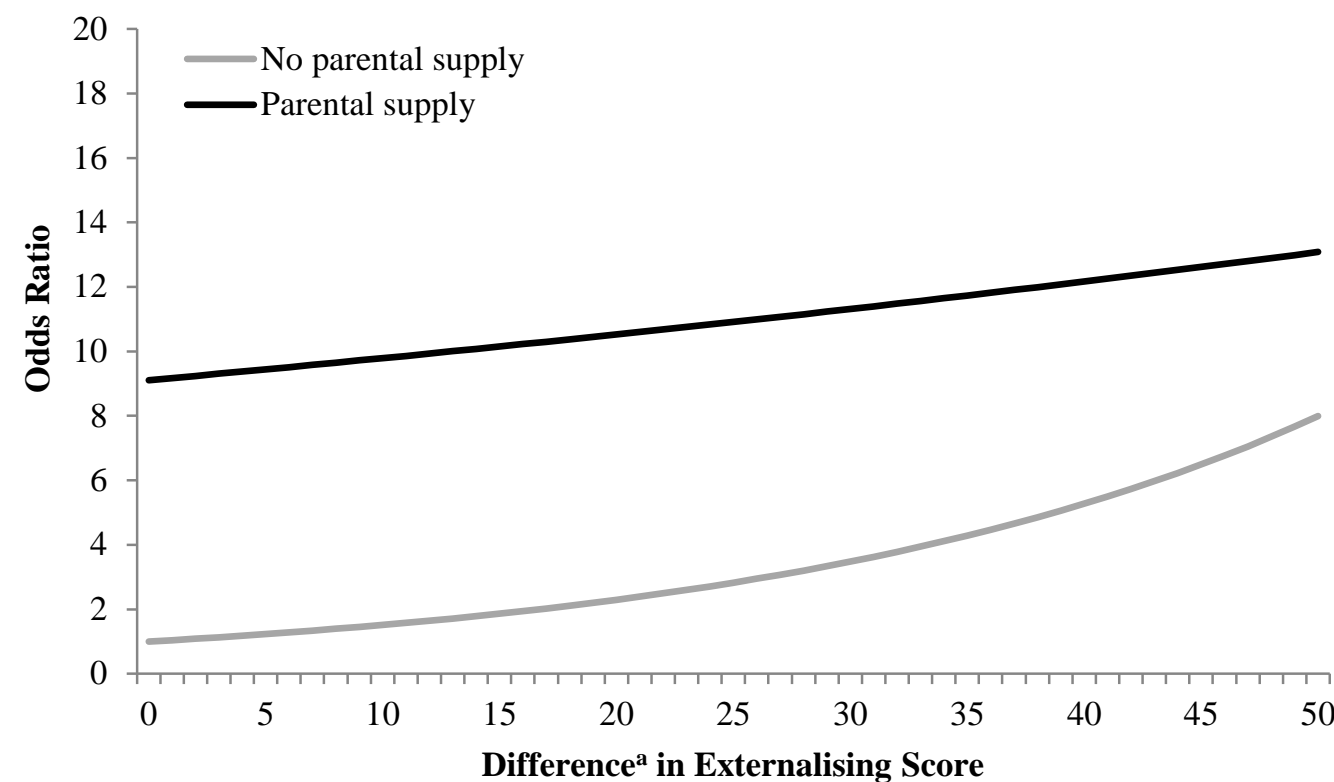

(b) Binge drinking $(p=0.002)$

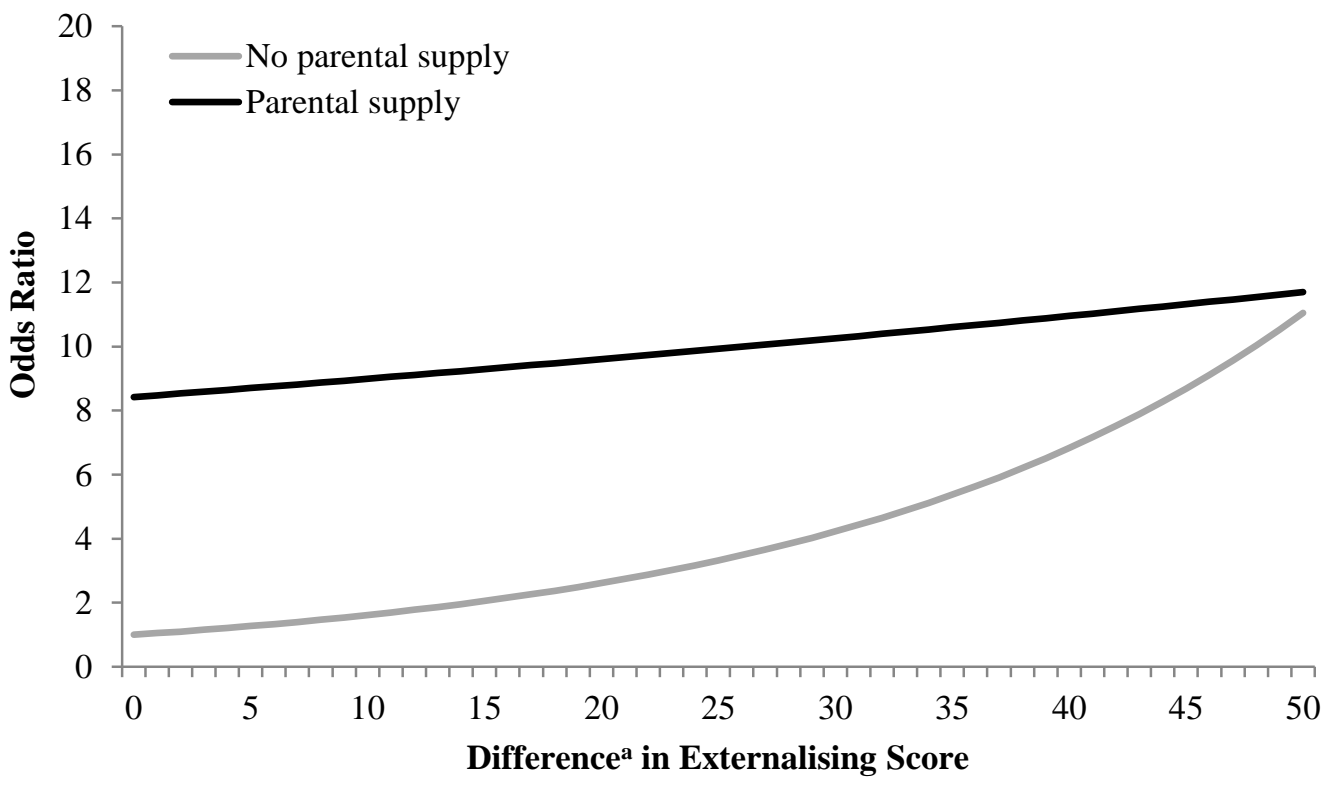

${ }^{a}$ These Figures present odds ratios (ORs) for varying differences in externalizing z-scores, irrespective of absolute score. That is, for example, comparing an externalizing score of 20 to a score of 10 will result in the same OR as comparing a score of 50 to a score of 40 (in both cases the difference in the two scores, 10, is the same). 
Figure S2 Interaction of parental supply and peer substance use

(a) Drinking whole drinks $(p<0.001)$

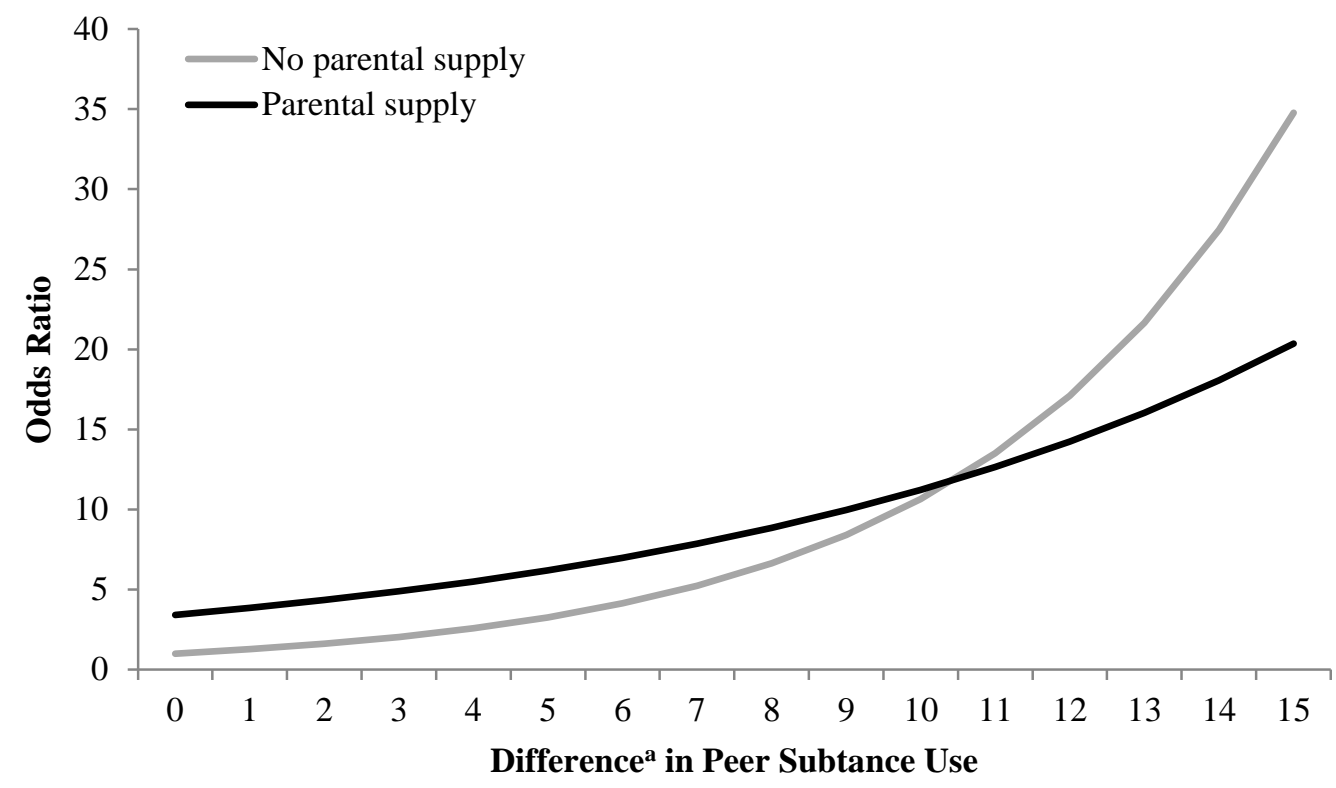

(b) Binge drinking $(p=0.035)$

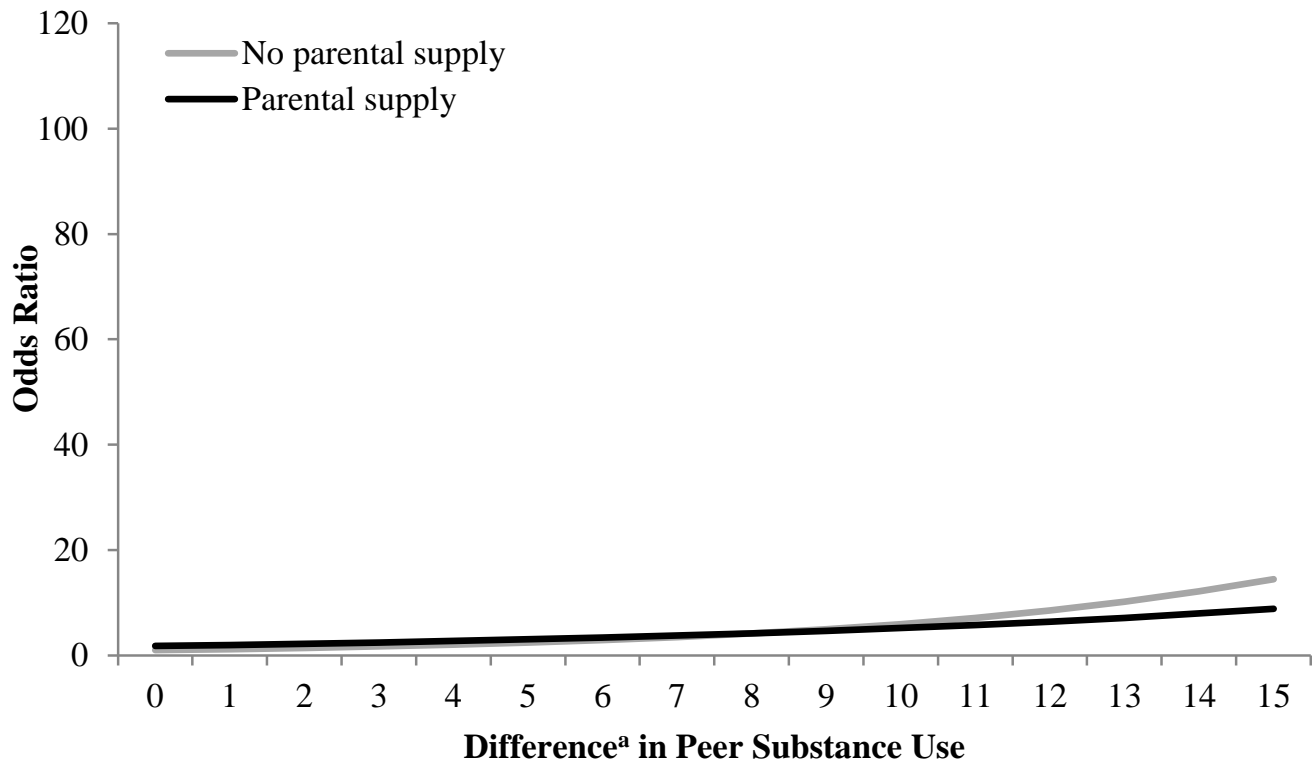

${ }^{a}$ These Figures present odds ratios (ORs) for varying differences in peer substance use score, irrespective of absolute score. That is, for example, comparing a peer substance use of 6 to a score of 1 will result in the same OR as comparing a score of 11 to a score of 6 (in both cases the difference in the two scores, 5 , is the same). 